\title{
BRAQUIÓPODOS MOSCOVIENSES (CHONETIDINA Y ORTHOTETIDA) DE LOS PAQUETES IMPRODUCTIVOS DE LA CUENCA CARBONÍFERA CENTRAL DE ASTURIAS (N DE ESPAÑA)
}

\author{
Luis Manuel RÍO GARCÍA \\ Departamento de Geología, Universidad de Oviedo, \\ c/Jesús Arias de Velasco s/n, 33005 Oviedo (España).
}

\begin{abstract}
Rí• García, L.M. 2002. Braquiópodos moscovienses (Chonetidina y Orthotetida) de los Paquetes Improductivos de la Cuenca Carbonífera Central de Asturias ( $\mathrm{N}$ de España). [Moscovian brachiopods (Chonetidina and Orthotetida) from the "Paquetes Improductivos" of the Asturian Central Coal Field (N of Spain).] Revista Española de Paleontologia, 17(1), 137-155. ISSN 0213-6937.
\end{abstract}

\begin{abstract}
This paper forms part of a Doctor's Thesis, dealing with the brachiopod content of the "Paquetes Improductivos" of the Asturian Central Coal Field. In this first chapter, only the Chonetidina and Orthotetida are included, the previous papers about brachiopods of the "Paquetes Improductivos" are discussed and descriptions of the brachiopod localities are given. The total amount of identified species is 24 . In the Sistematic chapter are described: Tomquistia? sp., Globosochonetes? merayoi n. sp., Rugosochonetes aff. latesinuatus (Schellwien, 1892), Rugosochonetes sp., Chonetinella globosa n. sp, Isochonetes? sp.1, Sokolskia sp.1, Meekella cf. eximia (Verneuil, 1845), and Schuchertella cf. gibba Manankov, 1979.
\end{abstract}

Keywords: Brachiopods, Chonetidina, Orthotetida, Moscovian, "Paquetes Improductivos", Central Coal Field, Cantabrian Mountains.

\section{RESUMEN}

Este trabajo representa la primera entrega de un estudio más amplio, realizado en una Tesis Doctoral, sobre el contenido en braquiópodos de los Paquetes Improductivos de la Cuenca Carbonífera Central de Asturias. En este primer capítulo, donde solamente se incluyen los braquiópodos representantes de Chonetidina y Orthotetida, se repasan los antecedentes en el estudio de braquiópodos procedentes de los Paquetes Improductivos de la Cuenca Carbonífera Central, y se describen las localidades de donde proceden las 24 especies identificadas. De todas estas, se describen en el capítulo Sistemática: Tornquistia? sp., Globosochonetes? merayoi n. sp., Rugosochonetes aff. latesinuatus (Schellwien, 1892), Rugosochonetes sp., Chonetinella globosa n. sp., Isochonetes? sp.1, Sokolskia sp. 1, Meekella cf. eximia (Verneuil, 1845), y Schuchertella cf. gibba Manankov, 1979.

Palabras clave: Braquiópodos, Chonetidina, Orthotetida, Moscoviense, Paquetes Improductivos, Cuenca Carbonífera Central, Cordillera Cantábrica.

\section{INTRODUCCIÓN}

Los primeros datos de braquiópodos procedentes de la Cuenca Carbonífera Central Asturiana datan del siglo XIX, y corresponden a de Verneuil (1846), Schulz (1858), Grand (1874), Mallada (1875, 1892), y Barrois (1882), coincidiendo estos estudios con el comienzo del creciente interés que esta unidad de la Zona Cantábrica fue adquiriendo debido a su riqueza en yacimientos de carbón. Durante la primera mitad del siglo XX, el estudio de los braquiópodos de la Cuenca Carbonífera Central, al igual que el del resto de los demás grupos de fósiles, fue bastante discontinuo, destacando las aportaciones de Delépine (1943), Patac (1944), Almela y Ríos (1953), Breimer, en Martínez Alvarez (1962), y Caride y García Loygorri (1968). Hay que esperar hasta la segunda mitad del siglo para la realización del primer estudio moderno sobre braquiópodos carboníferos de la Cordillera Cantábrica, por parte de Winkler Prins (1968). En dicho trabajo, que se refiere exclusivamente a los subórdenes 


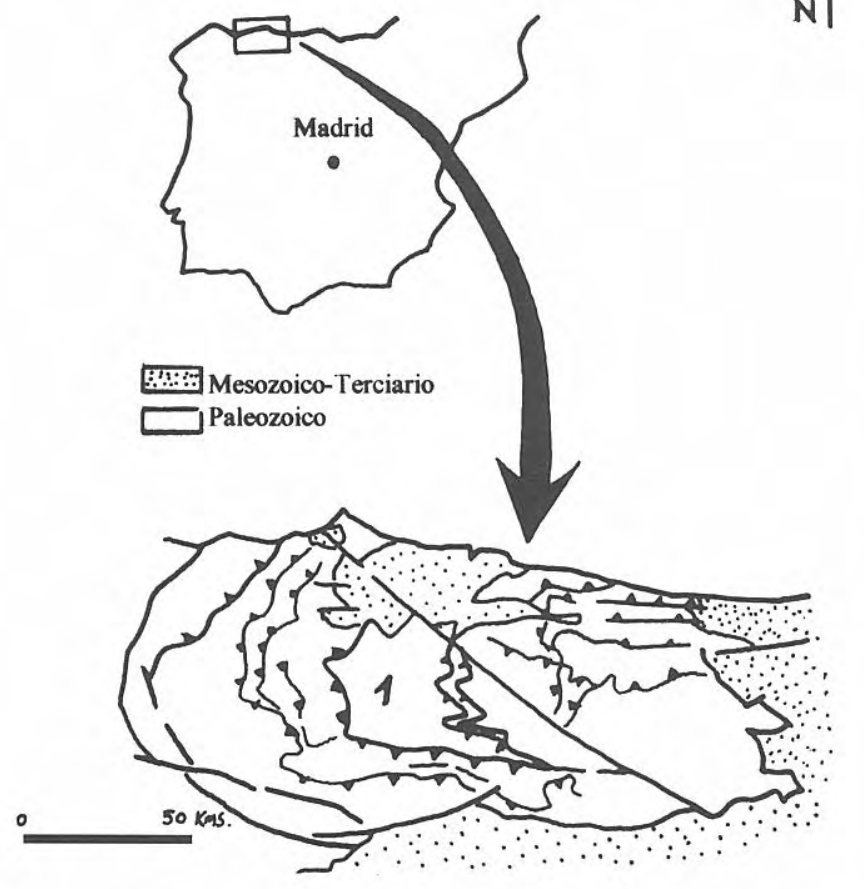

Figura 1. Mapa geológico simplificado de la Zona Cantábrica (según Pérez Estaún et al., 1988). 1: Cuenca Carbonífera Central.

Simplified geological map of the Cantabrian Zone (Pérez Estaún et al., 1988). 1: Central Coal Field.

Chonetidina y Productidina, hay una pequeña parte del material recolectado que procede de la Cuenca Carbonífera Central. Además, este mismo autor describe más braquiópodos de la Cuenca Carbonífera Central en un trabajo posterior: Van Amerom et al. (1970). Por último, hay que añadir el de Feys et al. (1974), que estudian los niveles productivos de la Cuenca.

Sin olvidar el trabajo previo de García Loygorri et al. (1971), no es hasta la celebración del X Congreso Internacional de Estratigrafía y Geología del Carbonífero, celebrado en España en 1983, cuando se produce un notable impulso en el avance sobre el conocimiento de la geología, y por lo tanto de la paleontología, de esta región de la Cordillera Cantábrica. Las citas de braquiópodos relacionadas con este evento corresponden a Martínez Chacón, que en Leyva y Gervilla (1983) y Luque et al. (1985), identifica un buen número de ellos dentro de la parte alta de la serie estratigráfica (Paquetes Productivos).

En los Paquetes Improductivos, situados en la parte inferior de la serie, las citas son escasas. Corresponden a Río García (1986), Martínez Chacón y Río García (1987), Río García y Martínez Chacón (1988), y Río García (1998). Cabe citar, además, la Tesis Doctoral de Río García (1993), donde se exploraron sistemáticamente los 4 Paquetes Improductivos de la Cuenca Carbonífera Central.

Este trabajo supone la primera entrega de los datos obtenidos en el transcurso de la mencionada Tesis
Doctoral, donde, además de la identificación y descripción de 96 especies de braquiópodos, se hacen consideraciones, principalmente, de tres tipos:

- Paleobiogeográficas. Se compara el contenido en braquiópodos de los Paquetes Improductivos de la Cuenca Central, con otras formaciones cantábricas de edad similar, con los Paquetes Productivos de la Cuenca Central, y con otras regiones del mundo.

- Paleoecológicas. Se aportan algunos datos sobre el tipo de fondo marino, así como de las condiciones energéticas del medio en el que vivían los braquiópodos.

- Edad de la fauna. Se establecen 3 asociaciones de braquiópodos: la vereyense, que caracteriza la parte inferior del Paquete Levinco, la kashiriense, que abarca la mitad superior del Paquete Levinco y al Paquete Llanón, y la podolskiense, que caracteriza al Paquete Tendeyón.

En esta primera entrega, se incluyen los 24 representantes de Chonetidina y Orthotetida, de los cuales se incluye la descripción de 9 especies. Del resto se aporta la sinonimia y yacimientos de donde procede el material; además, en algunos casos se incluye un apartado de discusiones. En las siguientes entregas se incluirá el resto de la sistemática, así como los capítulos a los que se ha hecho referencia anteriormente.

\section{MARCO GEOLÓGICO}

La Cuenca Carbonífera Central Asturiana es una de las unidades en las que Julivert (1971) y Pérez Estaún et al. (1988) dividieron la Zona Cantábrica (Fig. 1).

Por encima de su base estructural, de edad ordovícica o cambro-ordovícica, y de los términos más bajos de la sucesión carbonífera, representados por la "Caliza Griotte" (Fm. Alba, según Comte (1959), o Genicera, según Wagner et al. (1971), y la "Caliza de Montaña", se disponen unos $5000 \mathrm{~m}$ de materiales caracterizados por una alternancia de lutitas, limolitas, areniscas y carbón, con intercalaciones de bandas calcáreas, situadas preferentemente en la mitad inferior, conglomerados, y algún nivel volcánico.

Para Caride et al. (1973), la mayor parte de estos materiales, excepto una pequeña área en la zona occidental denominada Unidad de Riosa-Olloniego, que presenta algunas particularidades, están englobados en la llamada Unidad Aller-Nalón.

En esta unidad, García Loygorri et al. (1971), y García Loygorri (1974) dividieron la serie carbonífera por encima de la Caliza de Montaña en "Paquetes", dándole a este término, recogido de la terminología minera, una definición geológica y estratigráfica de la que carecía hasta entonces, ya que hasta ese momento dicho término solo hacía referencia a tramos con capas de carbón. En este trabajo se prefiere seguir usando el término paquete, en vez de formación, hasta que estas unidades no sean definidas formalmente como tales, si bien en algunos trabajos se ha usado el término formación para referirse a estas (Truyols, 1983).

Tradicionalmente, y sobre la base de su contenido en carbón, a los paquetes de la parte superior de la serie 


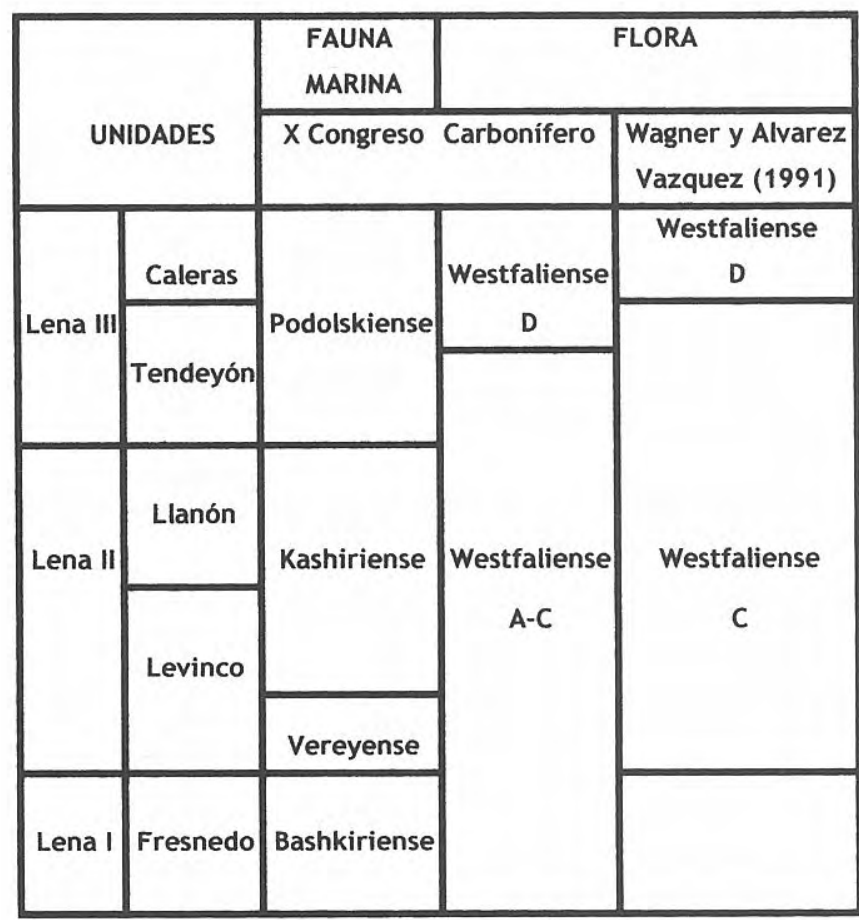

Figura 2. Edades atribuidas a los Paquetes Improductivos (y Caleras), y al Grupo Lena, según la fauna marina y la flora.

Age of the Paquetes Improductivos (and Caleras), and the Grupo Lena, according to marine faune and flora.

estratigráfica se les ha llamado Productivos por su riqueza en capas de carbón, y a los de la parte inferior se les ha denominado Improductivos por su escasez en capas de carbón. El espesor de estos últimos es de unos $2600 \mathrm{~m}$ y tienen un marcado carácter marino, abundando las intercalaciones calcáreas dentro de una monótona alternancia de lutitas, limolitas y areniscas. En orden ascendente, se denominan Fresnedo, Levinco, Llanón y Tendeyón.

En la vertiente sur de la Cuenca Carbonífera Central, hay algunas diferencias con respecto al resto de la Unidad donde, como ya hemos visto, los materiales situados por encima de la Caliza de Montaña se agrupan en paquetes. Debido a la imposibilidad de identificar los distintos paquetes, Aller (1986) propone la utilización de Grupo Lena para referirse a los Paquetes Improductivos más el inferior de los productivos: Caleras, y Grupo Sama para agrupar al resto de los Paquetes Productivos. Además, en la zona oriental de esta vertiente sur, diferencia 3 unidades dentro del Grupo Lena: Lena I (equivalente a Fresnedo), Lena II (equivalente a Levinco y Llanón), y Lena III (equivalente a Tendeyón y Caleras).

\section{EDAD DE LOS MATERIALES}

Como ya hemos apuntado anteriormente, la celebración en España del X Congreso Internacional de Geología y Estratigrafía del Carbonífero supuso un notable avance en el conocimiento de la edad de los materiales de la Cuenca Carbonífera Central. Las edades proporcionadas en dichos trabajos proceden tanto del estudio de floras continentales como de faunas marinas (Fig. 2).

Según las floras continentales, se asigna una edad Westfaliense A-C a los Paquetes Fresnedo, Levinco y Llanón (Leyva y Gervilla, 1983), estando el límite Westfaliense C-Westfaliense D dentro del Paquete Tendeyón (Leyva y Gervilla, 1983, Sáenz de Santa María et al., 1985 y Luque et al., 1985). Estos datos coinciden parcialmente con los aportados posteriormente por Wagner y Álvarez-Vázquez (1991), que consideran que el límite Westfaliense C-Westfaliense D está situado próximo a la base del Paquete Caleras, asignando una edad Westfaliense C a los Paquetes Levinco, Llanón y Tendeyón (los dos últimos, al Westfaliense C superior).

Respecto a la fauna marina, los foraminíferos contenidos en los paquetes inferiores parecen indicar que el límite Bashkiriense/Moscoviense está situado en la base del Paquete Levinco, el límite Vereyense/ Kashiriense estaría dentro de este mismo paquete, y el límite Kashiriense/Podolskiense, próximo al contacto entre Llanón y Tendeyón (Leyva y Gervilla, 1983, Martínez Díaz et al., 1985). Además, según Granados et al., 1985, el límite Bashkiriense/Vereyense estaría situado dentro del llamado "Nivel de Transición", donde coexistirían foraminíferos propios de ambos pisos.

Los braquiópodos no aportan muchos datos para el establecimiento de la edad de la sucesión dentro de los Paquetes Improductivos. Los únicos datos proceden de Río García (1986), Río García y Martínez Chacón (1988), quienes definen dentro del Paquete Levinco (corte de Los Tornos) 2 asociaciones de braquiópodos, una vereyense y otra kashiriense; y Río García (1993, 1998) donde se definen 3 asociaciones de braquiópodos para los Paquetes Improductivos: una vereyense, dentro de la parte inferior del Paquete Levinco, otra kashiriense, en la parte superior del Paquete Levinco y en el Paquete Llanón, y otra podolskiense, en el Paquete Tendeyón. Estos datos coinciden con los aportados por los foraminíferos.

\section{YACIMIENTOS DE BRAQUIÓPODOS}

Se describen a continuación las localidades de donde proceden los braquiópodos identificados en este trabajo. Estas localidades en unos casos pertenecen a secciones que abarcan paquetes enteros o partes de ellos, y en otros casos se trata de localidades aisladas dentro de un paquete (Fig. 3).

La litología más común en que se encuentra el material estudiado es la lutítica a limolítica, estando conservados, por lo tanto, la mayor parte de los ejemplares como moldes. Además, su estado de conservación no es bueno, lo que unido a que el número de ejemplares de cada especie que aparece en los yacimientos suele ser bastante bajo, hace que la clasificación del material sea complicada y se recurra muchas veces a la nomenclatura abierta.

\section{PAQUETE LEVINCO}

Tiene un espesor medio de $750 \mathrm{~m}$ y está compuesto por un conjunto de lutitas, limolitas y areniscas con alguna capa 

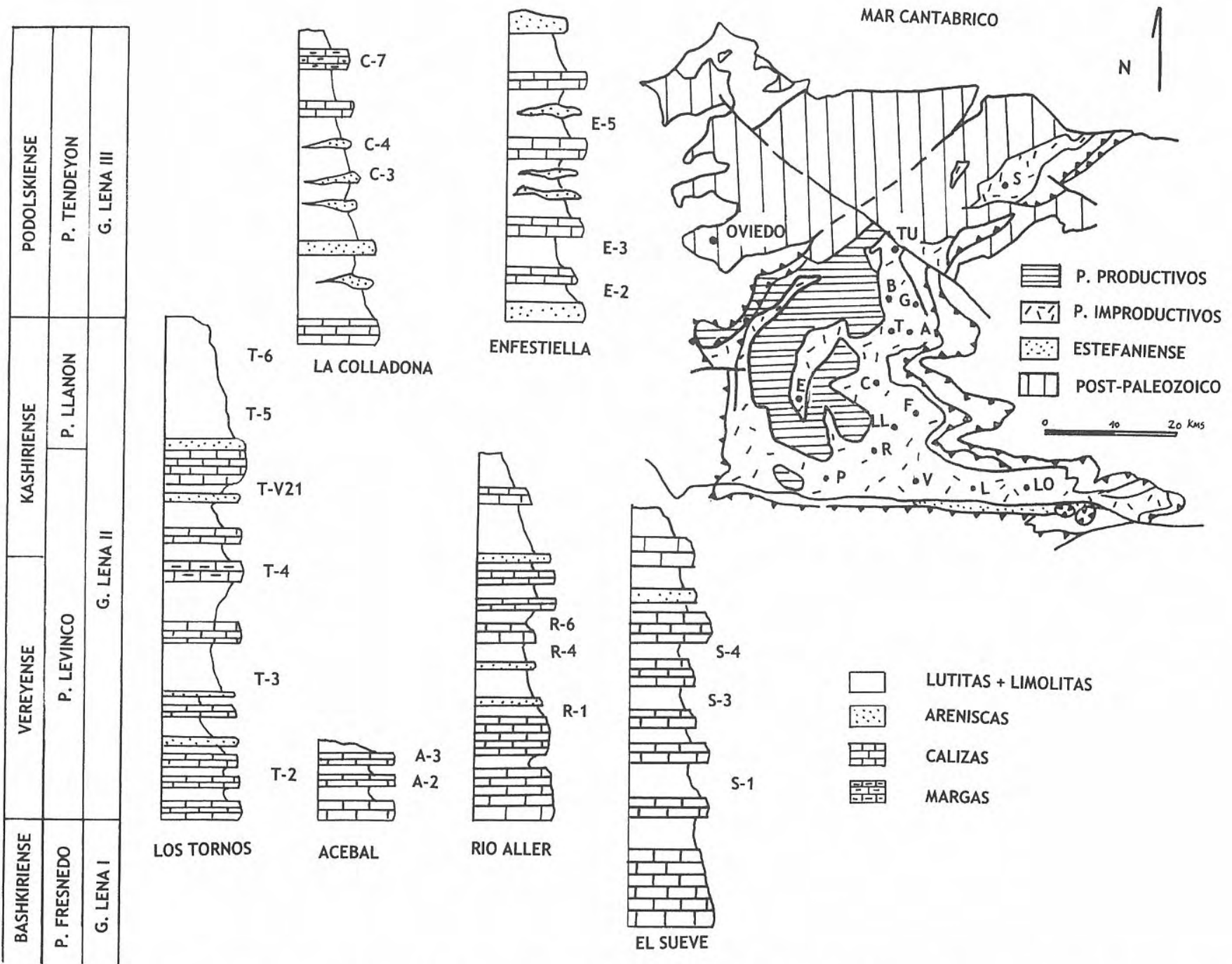

$\mathrm{N}$

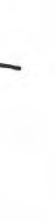

\section{PRODUCTIVOS}

Figura 3. Mapa geológico simplificado de la Cuenca Carbonífera Central (Truyols, 1983), mostrando las localidades de procedencia de los braquiópodos y las columnas estratigráficas simplificadas de las secciones estudiadas. $\underline{\text { Secciones. }}$ T: Corte de Los Tornos. A: Corte de Acebal. S: Corte del Sueve. R: Corte del Río Aller. C: Corte de La Colladona. E: Corte de Enfestiella. Localidades aisladas. L1: Llamas. L: Lillo. Tu: Tuenes. B: Baluga. G: Gamonal. F: La Fuente. P: Pendilla. V: Vegarada. Lo: Lois.

Simplified geological map of the Central Coal Field (Truyols, 1983), showing the collecting localities and the simplified stratigraphic sequences of the studied sections. Sections. T: Los Tornos section. A: Acebal section. S: El Sueve section. R: Río Aller section. C: La Colladona section. E: Enfestiella section. Isolated localities. Ll: Llamas. L: Lillo. Tu: Tuenes. B: Baluga. G: Gamonal. F: La Fuente. P: Pendilla. V: Vegarada. Lo: Lois.

de carbón, entre las que se intercalan 6 o 7 bandas calcáreas, cuyo número y espesor aumenta hacia el sur de la cuenca. Estos materiales están agrupados en varios ciclos sedimentarios (García Loygorri et al., 1971). En el borde oriental, la primera banda calcárea que aparece constituye la base del paquete, y se denomina Caliza de Peña Redonda. Hacia el borde occidental se resuelve en varias bandas calcáreas.

Las localidades con braquiópodos son las siguientes (Fig. 3):

T-2. Forma parte del corte de Los Tornos, al igual que las 3 siguientes localidades. Este corte fue estudiado durante la celebración del ya mencionado X Congreso Internacional del Carbonífero (Leyva y Gervilla, 1983). La litología del yacimiento consta de lutitas limosas gris oscuro a gris verdoso con fractura astillosa. Edad Vereyense. Localidad B-220/2 de Río García y Martínez Chacón (1988). Descrita en Río García (1993).

T-3. Alternancia de lutitas y limolitas. Edad Vereyense. Localidad B-223 de Río García y Martínez Chacón (1988). Descrita en Río García (1993).

T-4. Margas azuladas y lumaquélicas. Edad Kashiriense. Localidad B-226/8 de Río García y Martínez Chacón (1988). Descrita en Río García (1993).

T-V21. Alternancia de areniscas y lutitas, a $40 \mathrm{~m} \mathrm{del}$ techo del paquete. Edad Kashiriense. Localidad V-21 de Río García y Martínez Chacón (1988). Descrita en Río García (1993). 
A-2. Forma parte del corte de Acebal, al igual que la siguiente localidad, que está situado en la ladera que está frente al corte de Los Tornos. Lutitas carbonatadas gris claro a techo de la $2^{\mathrm{a}}$ banda calcárea del corte. Edad Vereyense. Descrita en Río García (1993).

A-3. Mismo nivel que la anterior, pero a un nivel topográfico inferior. Edad Vereyense. Descrita en Río García (1993).

R-1. Forma parte del corte del Río Aller, al igual que las 2 siguientes localidades, que fue estudiado por Martínez Álvarez (1962) y Barba (1991). Está situado a la altura de las Foces del Río Aller, en la carretera al Puerto de Vegarada. Se trata de unas lutitas carbonatadas marrón claro a techo de un nivel calcáreo, $160 \mathrm{~m}$ por encima de la base del corte. Edad Vereyense. Descrita en Río García (1993).

R-4. Lutitas carbonatadas gris oscuro, $90 \mathrm{~m}$ por encima del anterior yacimiento. Edad Vereyense. Descrita en Río García (1993).

R-6. Lutitas carbonatadas a techo de una caliza gris claro, $180 \mathrm{~m}$ por encima del anterior yacimiento. Edad Vereyense. Descrita en Río García (1993).

S-1. Forma parte del corte del Sueve, al igual que las 2 siguientes localidades. El corte fue estudiado por Villa (1995). La litología está compuesta por margas y lutitas, a techo de una banda calcárea. Está $50 \mathrm{~m}$ encima de la muestra SV-18 de dicha autora. Edad Vereyense. Descrita en Río García (1993).

S-3. Lutitas carbonatadas, a techo de una caliza donde está la muestra SV-25. Edad Vereyense. Descrita en Río García (1993).

S-4. Margas y lutitas, a techo de un nivel carbonatado, $50 \mathrm{~m}$ por encima de la anterior localidad. Edad Vereyense. Descrita en Río García (1993).

G-1. Se encuentra en las proximidades de Gamonal (Laviana). Lutitas carbonatadas intercaladas entre 2 niveles calcáreos. Edad Vereyense-Kashiriense. Descrita en Río García (1993).

G-2. Lutitas carbonatadas a techo de un nivel de caliza, $30 \mathrm{~m}$ por encima del anterior yacimiento. Edad VereyenseKashiriense. Descrita en Río García (1993).

B-1. Está situado en una pista que sale desde la Faya de los Lobos hacia el Este (Sierra de la Baluga). Se trata de unas lutitas carbonatadas de color negro intercaladas en el primer nivel calcáreo que se encuentra en la pista. Edad Vereyense-Kashiriense. Descrito en Río García (1993).

B-2. Caliza gris clara a muro del anterior yacimiento. Edad Vereyense-Kashiriense. Descrito en Río García (1993).

F-1. La localidad está situada al NE de La Fuente (Collanzo), a $1 \mathrm{~km}$ del pueblo y junto a un manantial. El yacimiento está en unas lutitas carbonatadas gris oscuro, a techo de una caliza gris clara. Edad Vereyense-Kashiriense. Descrita en Río García (1993).

\section{PAQUETE LLANÓN}

Su potencia media es de $500 \mathrm{~m}$. Está compuesto por una alternancia de lutitas, limolitas y areniscas, con micropudingas en la base, entre las que se intercala un tramo continental de $100 \mathrm{~m}$, con varias capas de carbón, englobadas en una secuencia característica (García Loygorri et al.,1971).
Las localidades con braquiópodos son las siguientes (Fig. 3):

T-5. Al igual que la siguiente localidad, está dentro del corte de Los Tornos, al que ya se ha hecho referencia en los yacimientos del Paquete Levinco. La litología está compuesta por lutitas gris azuladas, $50 \mathrm{~m}$ por encima de la base del paquete. Edad Kashiriense. Descrita en Río García (1993).

T-6. Lutitas gris azuladas a gris verdoso, $170 \mathrm{~m}$ por encima de la base del paquete. Edad Kashiriense. Descrita en Río García (1993).

Tu-1. Está situado en la primera banda calcárea que se encuentra en la carretera hacia Tuenes desde la carretera de Barredos a Nava. El yacimiento se encuentra en una alternancia de lutitas carbonatadas negras y margas. Probablemente esté próximo al límite de los Paquetes Llanón y Tendeyón (Kashiriense?-Podolskiense?). Descrita en Río García (1993).

\section{PAQUETE TENDEYÓN}

Tiene un espesor medio de $900 \mathrm{~m}$ y está formado por una alternancia de lutitas y limolitas con intercalaciones de cuarcitas y calizas, agrupada en varios ciclos sedimentarios con una secuencia característica (García Loygorri et al.,1971). 3):

Las localidades con braquiópodos son las siguientes (Fig.

C-3. Forma parte del corte de La Colladona, estudiado en el X Congreso Internacional del Carbonífero (Leyva y Gervilla, 1983), al igual que las 2 siguientes localidades. Se trata de unas lutitas y limolitas gris oscuro, $380 \mathrm{~m}$ por encima de la base del Paquete. Edad Podolskiense. Descrita en Río García (1993).

C-4. Alternancia de lutitas y limolitas, $420 \mathrm{~m}$ por encima de la base del Paquete. Edad Podolskiense. Descrita en Río García (1993).

C-7. Margas y lutitas carbonatadas, $580 \mathrm{~m}$ por encima de la base del Paquete. Edad Podolskiense. Descrita en Río García (1993).

E-2. Forma parte del corte de Enfestiella, situado en los alrededores del pueblo del mismo nombre, al igual que las 2 siguientes localidades. Fue estudiado por Casillas (1984) y Barba (1991). Lutitas carbonatadas de color ocre, a techo de la $1^{\text {a }}$ banda calcárea del corte. Edad Podolskiense. Descrita en Río García (1993).

E-3 Lutitas y limolitas de color marrón, a muro de la $2^{\text {a }}$ caliza del corte. Edad Podolskiense. Descrita en Río García (1993).

E-5. Lutitas carbonatadas de color ocre, a techo de la una banda calcárea, $270 \mathrm{~m}$ por encima de la anterior localidad. Edad Podolskiense. Descrita en Río García (1993).

Ll-1. Está situado en las proximidades de Llamas, al pie de un desvío que conduce a Conforcos. El yacimiento tiene una litología lutítica a limolítica, de color gris claro a negro con alternancias de niveles areniscosos. Edad Podolskiense. Descrita en Río García (1993).

\section{VERTIENTE SUR}

L-1. Se encuentra en los alrededores de Puebla de Lillo, en la carretera hacia Camposolillo. Por su posición 


\begin{tabular}{|c|c|c|c|c|c|c|c|}
\hline \multirow{3}{*}{$\begin{array}{l}\text { ESPECIES DE BRAQUIOPODOS } \\
\text { Tornquistia asturica } \\
\end{array}$} & \multicolumn{3}{|c|}{ LEVINCO } & LLANON & \multirow[b]{2}{*}{$?$} & \multirow{2}{*}{$\begin{array}{l}\text { TENDEYON } \\
\text { Podolskiense }\end{array}$} & \multirow{2}{*}{$\begin{array}{l}\text { GRUPO LENA } \\
\text { Verey. / Podols. }\end{array}$} \\
\hline & \multirow{2}{*}{$\frac{\text { Vereyense }}{\mathbf{x}}$} & \multirow[t]{2}{*}{$?$} & \multicolumn{2}{|c|}{ Kashiriense } & & & \\
\hline & & & & & & & \\
\hline T. diminuta & $x$ & & & & & & \\
\hline Tornquistia? sp. & & & & & & $x$ & \\
\hline Globosochonetes waldenburgianus & & & & $x$ & & & $x$ \\
\hline G. waldschmidti & $x$ & & $x$ & & & & $x$ \\
\hline G.?merayoi n.sp. & & $x$ & & & & & \\
\hline Rugosochonetes acutus & $\mathbf{x}$ & & & $x$ & & $x$ & \\
\hline R. cf. latesinuatus & $x$ & & & $x$ & & & \\
\hline R. aff. latesinuatus & & $x$ & & & & & \\
\hline R. skipseyi & $x$ & & $x$ & $x$ & & $x$ & \\
\hline Rugosochonetes sp. & & & & & $x$ & & \\
\hline Chonetinella crassiradiata & $x$ & & $x$ & & & & \\
\hline Ch. aff. flemingi & $x$ & & $\bar{x}$ & & & & \\
\hline Ch. cf. plebeia & $x$ & & & & & & \\
\hline Ch. globosa n. sp. & $x$ & & & & & & \\
\hline Chonetinella sp. & & & & & & $x$ & \\
\hline N. (Neochonetes) babianus & $x$ & & & & & & \\
\hline Tsochonetes? sp.1 & $x$ & & & & & & \\
\hline Tsochonetes? sp.2 & $x$ & & $x$ & $x$ & & & \\
\hline Sokolskya sp.1 & & & & $x$ & & & \\
\hline Sokolskya sp.2 & $x$ & & & & & & \\
\hline Meekella cf. eximia & & & & $x$ & & & \\
\hline Schuchertella sajakensis asturica & & & & & & $x$ & \\
\hline S. cf.gibba & $x$ & & $x$ & $x$ & & $x$ & \\
\hline
\end{tabular}

Tabla 1. Distribución estratigráfica, en este trabajo, de las especies de braquiópodos recolectadas. Stratigraphic range, in this work, of the collected brachiopod species.

cartográfica, posiblemente está en la parte baja de la Unidad Lena II (Moscoviense Inferior). Intercalación de lutitas y limolitas en un nivel carbonatado. Descrita en Río García (1993).

V-1. Está situado en los alrededores de Cerulleda, a donde se llega por la carretera del Puerto de Vegarada. Geológicamente se ubica dentro de la Unidad Lena II (Moscoviense Inferior). Alternancia de lutitas y limolitas, situadas en el Km 21,00 de la carretera del Puerto de Vegarada. Descrita en Río García (1993).

Lo-1. La localidad está en el extremo suroriental de la Cuenca Carbonífera Central y se encuentra en la carretera que cruza el desfiladero del río Dueñas, al sur del pueblo de Lois. Este corte ha sido estudiado por Barba et al. (1991). El yacimiento está en unas lutitas marrones y margas de color gris oscuro, dentro de las Calizas de Bachende (Podolskiense). Estas calizas, cuya potencia es de unos 650 $\mathrm{m}$, son comparables a materiales de la Unidad Lena II y a los Paquetes Levinco y Llanón. Descrita en Río García (1993).

P-1. Está situado en los alrededores de Pendilla, a donde se llega tomando un desvío de la nacional 630, a la altura de Busdongo. Se trata de afloramientos parciales de la serie que pertenecen a la Unidad Lena (Moscoviense Inf.). Lutitas y limolitas gris oscuro, en la pista que sale de Pendilla hacia El Cellón, a 1 Km de Pendilla. Descrita en Río García (1993).

\section{SISTEMÁTICA}

El número de especies de Chonetidina y Orthotetida identificadas en el transcurso de este trabajo, y que proceden de las localidades mencionadas más arriba, es de 24 , agrupadas en 9 géneros (Tabla 1). De estas 24 especies se describen en este capítulo 9: Globosochonetes? merayoi $\mathrm{n}$. sp. y Chonetinella globosa n. sp., por tratarse de nuevas especies; Tornquistia? sp., por las características de sus papilas internas; Rugosochonetes aff. latesinuatus, por tratarse posiblemente de un nuevo taxón; Rugosochonetes sp., por ser una forma que presenta características distintivas del resto de especies de Rugosochonetes conocidas en la Cordillera Cantábrica; e Isochonetes? sp.1, Sokolskia sp.1, Meekella cf. eximia y Schuchertella cf. gibba por tratarse de taxones poco o nunca descritos en la Cordillera Cantábrica.

Del resto de taxones, en el caso de especies ampliamente citadas y descritas en la Cordillera Cantábrica, solo se 
incluyen la sinonimia y el material recolectado. En otros casos se incluye, además, algún tipo de discusión.

Todos los ejemplares están depositados en el Departamento de Geología de la Universidad de Oviedo.

En las descripciones se usan las abreviaturas L y A para referirse a la longitud y a la anchura de la concha.

Se ha seguido la sistemática del Treatise on Invertebrate Paleontology (Kaesler, ed., 2000), Part H, Brachiopoda (revised).

\section{FILO BRACHIOPODA Duméril, 1806 SUBFILO RHYNCHONELLIFORMEA Williams y otros, 1996 \\ CLASE STROPHOMENATA Williams y otros, 1996 \\ ORDEN PRODUCTIDA Sarytcheva y Sokolskaya, 1959 \\ SUBORDEN CHONETIDINA Muir-Wood,1955 \\ Superfamilia Chonetoidea Bronn, 1862 \\ Familia Anopliidae Muir-Wood,1962}

\section{Discusión}

Desde que Muir-Wood (1962) creó Anopliinae como una subfamilia dentro de Chonetidae, han sido muchos los intentos de clasificar este grupo de chonétidos: Rowell (1967), Boucot y Harper (1968), que elevan al grupo a la categoría de familia; Archbold (1980), que usa la ornamentación exterior para definir 2 subfamilias dentro de Anopliidae, de tal manera que las formas lisas pertenecen a Anopliinae, y las costuladas a Caenanopliinae; Afanasjeva (1984), que según el interior dorsal separa la familia en 2 subfamilias: Anopliinae, con un buen desarrollo de septos laterales, y Tornquistiinae con papilas en filas radiales.

Todos estos estudios asumen que el grupo es monofilético, dando además una gran importancia a una única característica para clasificar la familia. Con estos antecedentes Hanger y Strong (2000), hacen un análisis filogenético de la familia basado en métodos cladistas. El resultado es la confirmación de que la familia no es monofilética, estando dividida en 3 grupos. Por una parte Tornquistia, y por otra parte 2 grupos. Uno caracterizado por un umbo prominente, donde se incluyen los géneros carboníferos Globosochonetes, Caenanoplia, y Trichochonetes. El otro estaría caracterizado por la presencia de más de 2 septos laterales en la valva dorsal. Aquí están incluidos los géneros carboníferos, Subglobosochonetes y Anopliopsis. Además, según este estudio, algunos géneros con un tamaño más grande de lo normal para Anopliidae quedarían fuera de la familia, como Costachonetes, género con el que se compara más adelante Globosochonetes? merayoi n. sp.

En este trabajo se sigue la clasificación propuesta por Archbold (1980), recogida en Racheboeuf (1998) y Kaesler (2000), mientras no se incorporen formalmente en una revisión del grupo los resultados filogenéticos aportados por Hanger y Strong (2000).

Subfamilia Anopliinae Muir-Wood,1962 Tornquistia Paeckelmann,1930

Especie tipo: Leptaena (Chonetes) polita McCoy, 1855.

\section{Tornquistia asturica Río García y Martínez Chacón,1988}

*v1988 Tornquistia asturica n. sp.; Río García y Martínez Chacón, p. 41, figs. 4 k-1.

\section{Material}

T-2: 1 molde interno dorsal, 1 molde interno ventral, 1 molde externo ventral y 1 exterior ventral, DPO 111877 111880.

\section{Tornquistia diminuta (Demanet,1949)}

1943 Chonetes (Lissochonetes) minutus sp. nov.; Demanet, p. 72, lám. I, figs. 20-22.

*1949 Chonetes (Lissochonetes) diminutus nom. nov.; Demanet, p. 5.

.1968 Tornquistia diminuta (Demanet,1949); Winkler Prins, p. 112, text.figs. 17 a-b.

\section{Material}

G-1: 1 molde interno ventral, 1 molde externo dorsal con algún fragmento del molde interno dorsal, 1 molde ventral interno y externo, DPO 28617-28619.

\section{Tornquistia? sp.}

Fig. 4 a-e

\section{Material}

Tu-1: 3 moldes externos dorsales, 1 valva dorsal, DPO 28620-28623. C-4: 2 moldes ventrales internos y externos, 1 molde interno ventral, 1 molde externo dorsal, DPO 2862428627. C-7: 1 molde interno ventral, DPO 28628.

\section{Descripción}

Concha de tamaño pequeño (L: 4-6 mm, A: 12-18 mm), concavoconvexa, muy transversa, con la relación $\mathrm{L} / \mathrm{A}=1 / 3$. Contorno subrectangular redondeado, extremidades cardinales apuntadas, y máxima anchura en la charnela. El espesor de la concha es muy pequeño.

Valva ventral moderadamente convexa, con la máxima convexidad en la zona media de la concha. Orejetas grandes y separadas suavemente del resto de la concha. Interárea muy baja, disponiéndose a lo largo de ésta 3 o 4 pares de espinas, que forman un ángulo de $60^{\circ}$ respecto a la charnela. Seno ausente.

Valva dorsal cóncava, con la curvatura adaptándose a la de la ventral, e interárea más baja.

Ambas valvas son lisas, no observándose costillas ni lamelas concéntricas.

Interior ventral con campo muscular alargado y estrecho, restringido a la región umbonal. Está recorrido por un corto septo medio que no excede la longitud del campo muscular. La superficie interna está cubierta de papilas que, a diferencia de las papilas típicas, tienen un grosor bastante menor. Además, no parecen seguir un patrón determinado de distribución, estando más espaciadas y en un menor número.

Interior dorsal con proceso cardinal pequeño y bilobado posteriormente. Restantes caracteres no observados. 

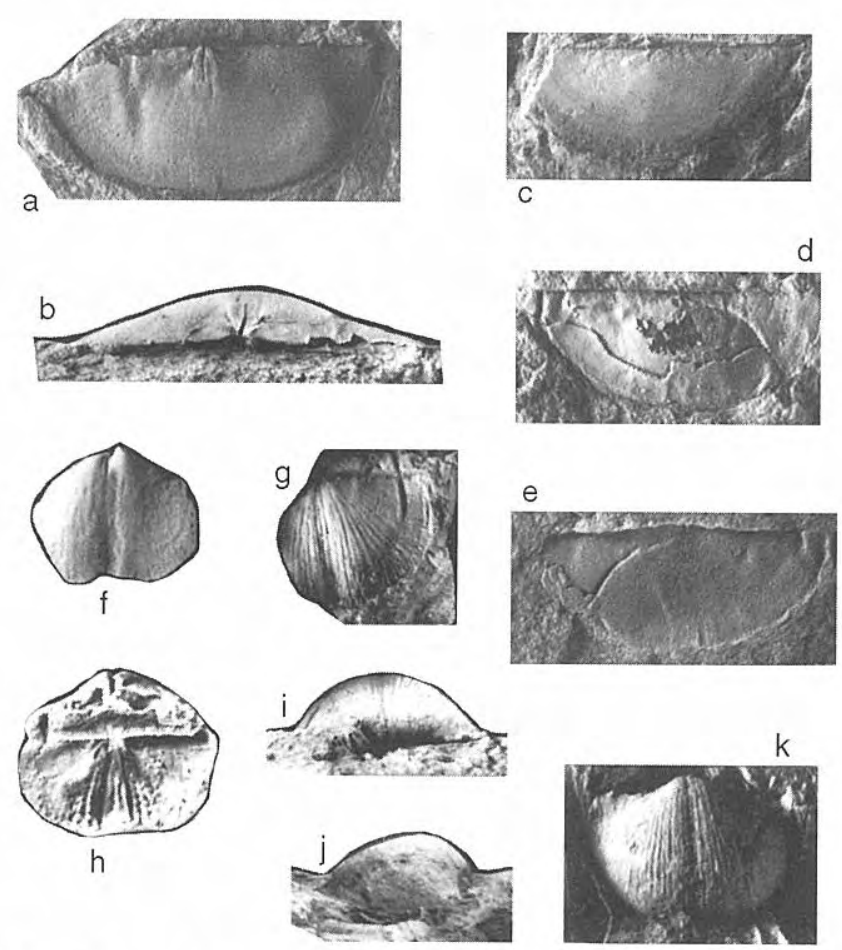

Figura 4. a-e. Tornquistia? sp. a-b: molde interno ventral en vistas ventral y posterior (x3). DPO 28624. Localidad C-4. c: molde externo dorsal (x3). DPO 28623. Localidad Tu-1. d-e: molde ventral interno y externo. DPO 28625. Localidad C-4. f-k. Globosochonetes? merayoi $\mathrm{n}$. sp. Todos los ejemplares proceden de la localidad B-1. f-h: Holotipo. Molde interno ventral, molde dorsal externo e interno (x4). DPO 28897. i-k: Paratipo. Valva ventral en vistas posterior, lateral y ventral (x4). DPO 28898. a-e. Tornquistia? sp. $\boldsymbol{a}-\boldsymbol{b}$ : internal mould of ventral valve in ventral and posterior views (x3). DPO 28624. Locality C-4. c: external mould of dorsal valve (x3). DPO 28623. Locality Tu-1. d-e: internal and external moulds of ventral valve. DPO 28625. Locality $C-4 . f-k$. Globosochonetes? merayoi $n$. sp. Locality B-1. $\boldsymbol{f}$ - $h$ : Holotype. Internal mould of ventral valve, external and internal moulds of dorsal valve (x4). DPO 28897. $i$ - $k$ : Paratype. Ventral valve in posterior, lateral and ventral views (x4). DPO 28898.

\section{Discusión y comparaciones}

Las características de las papilas internas: muy delgadas, en escaso número y distribuidas irregularmente, son distintas a las descritas hasta ahora en los chonétidos de la Cordillera Cantábrica, si bien hay que tener en cuenta que a veces representantes del género, especialmente si se trata de ejemplares juveniles, pueden presentar una pseudopuntuación algo irregular.

Aproximamos este material a Tornquistia por la forma de la concha y por su ornamentación, si bien difiere de los típicos Tornquistia por su septo medio ventral más corto, aunque también ha sido citado un septo medio ventral muy corto en Tornquistia cf. T. polita por Martínez Chacón y Winkler Prins (1977).
Se diferencia de las otras especies de Tornquistia identificadas es este trabajo, $T$. asturica y $T$. diminuta, por las características de las papilas, citadas anteriormente. Además, es mucho más transversa y no tiene seno y pliegue.

\section{Distribución}

Procede de los paquetes Llanón? y Tendeyón (Kashiriense?-Podolskiense). El género se conoce del Devónico Sup.? - Pérmico de Europa Occidental, Plataforma Rusa y Asia.

\section{Subfamilia Caenanopliinae Archbold, 1980 Globosochonetes Brunton, 1968}

Especie tipo: Globosochonetes parseptus Brunton, 1968.

\section{Globosochonetes waldenburgianus (Paeckelmann,1930)}

* 1930 Chonetes (? Plicochonetes) waldenburgianus nov. spec., Paeckelmann, p. 310, lám. 24, figs. 8-9.

v.1979 Globosochonetes waldenburgianus (Paeckelmann, 1930); Martínez Chacón, p.108, lám. 10, figs. 7-11.

\section{Material}

F-1: 1 molde externo ventral y dorsal, DPO 28592. L-1: 1 molde externo ventral, DPO 28593. T-5: 1 molde externo ventral, DPO 28594. T-6: 4 moldes externos ventrales, 5 moldes internos ventrales, 3 moldes externos dorsales y 4 moldes internos dorsales, DPO 28595-28610.

\section{Globosochonetes waldschmidti (Paeckelmann,1930)}

* 1930 Chonetes (Plicochonetes) waldschmidti nov. spec. Paeckelmann, p. 319, lám. 24, figs. 21-22.

.1968 Plicochonetes waldschmidti Paeckelmann, 1930; Winkler Prins, p. 118, lám. 9, figs. 1-2.

v.1979 Globosochonetes waldschmidti (Paeckelmann, 1930); Martínez Chacón, p.110, lám.10, figs.12-16.

v.1988 Globosochonetes waldschmidti (Paeckelmann, 1930); Río García y Martínez Chacón, figs. 4 i-j.

\section{Material}

F-1: 1 molde ventral interno y externo, DPO 28611. L-1: 2 moldes internos dorsales, 2 moldes internos ventrales, DPO 28612-28615. S-1: 1 valva ventral, DPO 28616. T-3: 2 moldes internos ventrales y dorsales, 1 molde interno dorsal, 1 molde externo ventral, DPO 111882-111885. T-4: 1 valva ventral, DPO 111886.

\section{Globosochonetes? merayoi n. sp.} Fig. $4 \mathrm{f}-\mathrm{k}$

Derivatio nominis: Especie dedicada al geólogo Cándido Merayo Vega. 


\section{Material}

Holotipo: molde interno ventral y molde dorsal interno y externo, DPO 28897. Paratipos: 2 valvas ventrales, DPO 28898-28899, y 2 moldes externos ventrales, DPO 2890028901 .

\section{Estrato y localidad típicos}

Lutitas carbonatadas de color negro, intercaladas en el primer nivel calcáreo reconocible a escala cartográfica que se encuentra en la pista que sale del Alto de la Faya de los Lobos, en dirección a la Sierra de La Baluga. Yacimiento B1, Paquete Levinco (Vereyense-Kashiriense).

\section{Diagnosis}

Caenanopliinae de pequeño tamaño, bastante concavoconvexo, contorno subrectangular redondeado y con las extremidades rectas. Valva ventral con seno muy estrecho y constante, tanto en profundidad como en anchura, a lo largo de toda la valva.

Small Caenanopliinae, quite concavo-convex, rounded sub-rectangular outline, and with straight cardinal extremities. Ventral valve with very narrow and regularly developed sulcus: the width and depth are constant along the valve.

\section{Descripción}

Concha de pequeño tamaño (L: 3-3,5 mm, A: 5-6 mm), transversa, muy concavoconvexa, con la charnela igual a la máxima anchura, y de contorno subrectangular redondeado. Estructura de la concha pseudopuntuada.

Valva ventral muy convexa, con orejetas muy pequeñas y aplanadas, formando las extremidades cardinales un ángulo recto. Máxima anchura en la charnela. Un seno estrecho y poco profundo recorre toda la valva, manteniendo constante su profundidad y anchura.

Valva dorsal cóncava, adaptándose a la forma de la ventral. Un pliegue, de las mismas características que el seno ventral, recorre toda la valva.

Ornamentación de ambas valvas a base de finas costillas intercalantes, alcanzando en el frente una densidad de 14 en $2 \mathrm{~mm}$. Sobre las costillas se han observado orificios, que debían de servir como salida de espínulas.

Interior ventral con septo medio muy alto y corto, que se extiende aproximadamente $1 / 5$ de la longitud de la valva. Campo muscular no visible. Superficie interna cubierta de filas radiales de papilas, fundamentalmente en los extremos de la valva.

Interior dorsal con alvéolo bastante desarrollado, crestas internas poco divergentes respecto de la charnela y pequeños anderidios divergiendo hacia la región anterior $75^{\circ}-80^{\circ}$. Los 2 septos divergentes se extienden, por lo menos, hasta más allá de la mitad de la valva, formando entre sí un ángulo de unos 25-30 grados. Superficie interna con filas radiales de papilas.

\section{Discusión y comparaciones}

El presente material se aproxima a varios géneros de Caenanopliinae. Costachonetes Waterhouse, 1975 se acerca por la presencia de un estrecho seno ventral, al menos en la parte posterior de la valva, si bien tiene una valva ventral más hinchada y un septo medio dorsal del que carece nuestro material. Además, Costachonetes es de mayor tamaño. Costachonetina Waterhouse, 1981 se aproxima por su exterior, con la presencia de seno y pliegue netos y estrechos. Sin embargo, el interior dorsal es distinto: septo medio corto y 2-4 pares de septos accesorios. También es comparable a Globosochonetes, si bien no se han citado en este género formas con pliegue y seno. Además, en Globosochonetes el interior dorsal puede presentar un septo medio en individuos gerónticos, y el ángulo de divergencia de los anderidios es de $90^{\circ}$, mientras en nuestro ejemplares es de $75^{\circ}-80^{\circ}$.

Considerando que pudiera tratarse de un nuevo género, finalmente se ha optado por aproximar nuestro material a Globosochonetes, por ser un género ampliamente citado en la Cordillera Cantábrica, a diferencia de los otros 2 géneros mencionados anteriormente. Además, la ausencia de septo medio dorsal puede deberse a que nuestros ejemplares no sean individuos gerónticos. El ángulo de divergencia de los anderidios y la presencia de seno y pliegue, nunca citados en Globosochonetes, hace que aproximemos el material a este género con reservas.

Se diferencia del resto de las especies de Globosochonetes identificadas en este trabajo, $G$. waldenburgianus, $G$. cf. waldenburgianus y $G$. waldschmidti, por la presencia de seno y pliegue. Además, de las 2 primeras se separa por su contorno y de la última por su mayor convexidad.

Por el tamaño de la valva, así como por la presencia de seno y pliegue, pudiera compararse a Chonetinella globosa n. sp., descrita más adelante en este trabajo. Se diferencian por el contorno subcircular y costillas más anchas de esta última. Además, Ch. globosa n. sp. también tiene el septo medio ventral más largo, así como el seno y pliegue más profundos.

\section{Distribución}

Procede del Paquete Levinco (Vereyense-Kashiriense).

Familia Rugosochonetidae Muir-Wood,1962, emend. Martínez Chacón y Winkler Prins, 2000

Subfamilia Rugosochonetinae Muir-Wood, 1962 Rugosochonetes Sokolskaja,1950

Especie tipo: Orthis hardrensis Phillips, 1841.

\section{Rugosochonetes acutus (Demanet,1938)}

* 1938 Chonetes (Chonetes) laguessianus acutus Demanet; Demanet, en Demanet y Van Straelen, p. 120, lám. 108, figs. 8-10.

1938 Chonetes (Chonetes) laguessianus transversalis Demanet; en Demanet y Van Straelen, p. 120, lám. 108, figs. 11-13.

1968 Rugosochonetes acutus (Demanet, 1938); Winkler Prins, p. 114, lám. 9, fig. 8. 


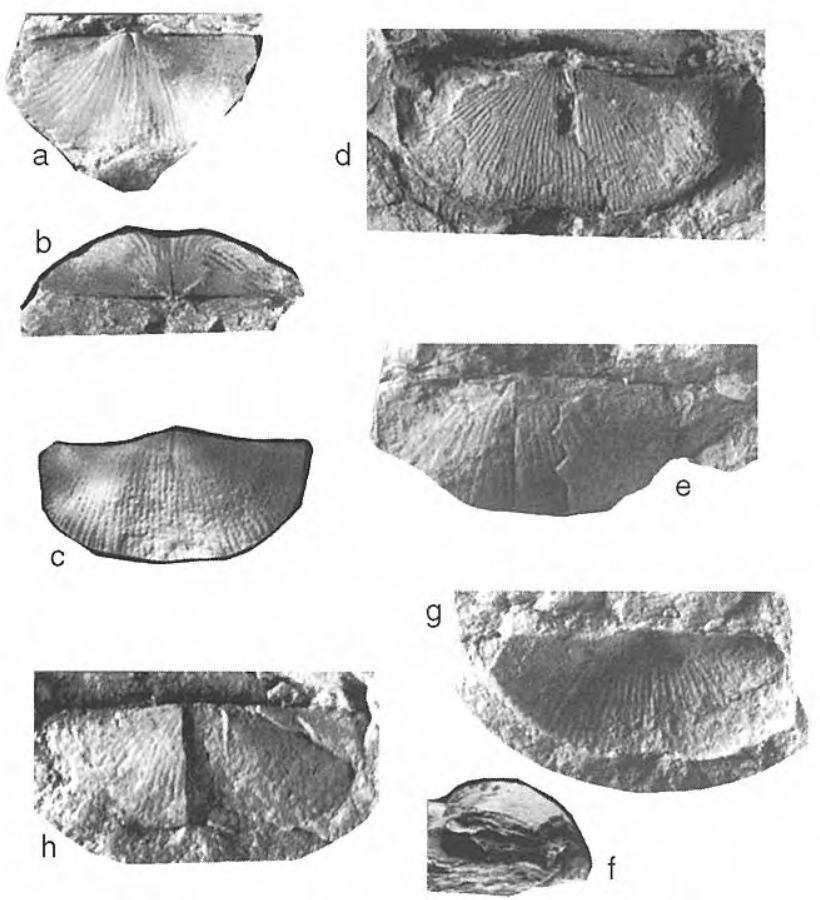

Figura 5. a-c. Rugosochonetes cf. latesinuatus (Schellwien, 1892). a-b: molde interno ventral en vistas ventral y posterior (x2). DPO 28559. Localidad T-6. c: molde interno ventral (x2). DPO 111900. Localidad T-2. d. $R$. aff. latesinuatus (Schellwien, 1892). Molde externo dorsal (x2). DPO 28561. Localidad B-1. e-h. Rugosochonetes sp. Todos los ejemplares proceden de la localidad Tu-1. e-f: molde interno ventral parcialmente roto dejando ver parte del molde externo dorsal, en vistas ventral y lateral (x3). DPO 28910. g: molde externo ventral del mismo ejemplar (x3). DPO 28910. h: molde interno ventral (x3). DPO 28909. $a-c$. Rugosochonetes $c f$. latesinuatus (Schellwien, 1892). $\boldsymbol{a}$ - $\boldsymbol{b}$ : internal mould of ventral valve in ventral and posterior views (x2). DPO 28559. Locality T-6. $c$ : internal mould of ventral valve (x2). DPO 111900. Locality T-2. d. R. aff. latesinuatus (Schellwien, 1892). External mould of dorsal valve (x2). DPO 28561. Locality B-1. e-h. Rugosochonetes $s p$. Locality Tu-1. e-f: internal mould of ventral valve, somewhat decorticated, showing part of the external mould of the dorsal valve, in ventral and lateral views (x3). DPO 28910. $g$ : external mould of ventral valve of the same specimen (x3). DPO 28910. h: internal mould of ventral valve (x3). DPO 28909.

v.1979 Rugosochonetes acutus (Demanet, 1938); Martínez Chacón, p. 94, lám. 8, figs. 10-16.

v.1988 Rugosochonetes acutus (Demanet, 1938); Río García y Martínez Chacón, fig. 4-b.

\section{Material}

A-3: 1 molde interno dorsal incompleto, DPO 28554. T2: 3 moldes externos dorsales, DPO 111887-111889. T-5: 1 molde interno ventral, 1 molde externo ventral y dorsal, 1 molde externo dorsal, DPO 28555-28557. C-3: 1 molde interno dorsal y externo dorsal, DPO 28558. S-1: 2 valvas ventrales, DPO 28572-28573.

\section{Rugosochonetes $\mathrm{cf}$. latesinuatus (Schellwien,1892) \\ Fig. 5 a-c}
v.1988 Rugosochonetes cf. latesinuatus (Schellwien, 1892); Río García y Martínez Chacón, p. 40, fig. $4 \mathrm{e}-\mathrm{g}$.

\section{Material}

T-2: 2 moldes externos dorsales, 1 molde interno ventral, 1 molde interno dorsal, DPO 111898-111901. T-6: 2 moldes internos ventrales, DPO 28559-28560.

\section{Rugosochonetes aff. latesinuatus (Schellwien, 1892) \\ Fig. 5 d}

Material

B-1: 1 molde externo dorsal, DPO 28561.

\section{Descripción}

Valva dorsal de tamaño grande para el género (L: $8 \mathrm{~mm}$, A: $19 \mathrm{~mm}$ ), transversa y con el contorno subrectangularredondeado. Bastante cóncava y con la interárea alta (2 $\mathrm{mm}$ ). Máxima anchura en la charnela, formando las extremidades cardinales un ángulo de unos 80-85 grados. Orejetas aplanadas. Un pliegue no muy patente, ancho y de techo redondeado, recorre la valva desde la región posterior a la anterior, donde se abre hasta alcanzar la mitad de la anchura total de la valva.

Ornamentación a base de costillas finas y redondeadas, que aumentan en número por intercalación hasta alcanzar una densidad de 8 en $2 \mathrm{~mm}$.

Proceso cardinal tetralobado posteriormente.

\section{Discusión y comparaciones}

El material del que se dispone es muy escaso, un molde externo dorsal. Se asemeja a $R$. latesinuatus por su tamaño, forma del pliegue y ser igualmente transversos, sin embargo, se diferencia por tener unas costillas más finas ( 8 en $2 \mathrm{~mm}$, frente a 5 en $2 \mathrm{~mm}$ ), y un pliegue menos acusado. Pudiera, por lo tanto, tratarse de un nuevo taxón. De la forma aquí descrita como $R$. cf. latesinuatus se diferencia por su mayor tamaño y sus costillas más finas.

\section{Distribución}

Procede del Paquete Levinco (Vereyense-Kashiriense).

\section{Rugosochonetes skipseyi (Currie,1937)}

* 1937 Chonetes hardrensis (Phillips) var. skipseyi var. nov. Currie; en Currie, Duncan y Muir-Wood, p. 420, lám. 2, fig. 4. 
1968 Rugosochonetes skipseyi (Currie, 1937); Winkler Prins, p. 115, lám. 9, figs. 6-7.

v.1979 Rugosochonetes skipseyi (Currie,1937); Martínez Chacón, p. 97, lám. 8, figs. 17-22; lám. 9, fig. 1.

v.1988 Rugosochonetes skipseyi (Currie,1937); Río García y Martínez Chacón, fig. 4-d.

\section{Material}

T-4: 1 molde interno ventral, 1 molde externo dorsal, DPO 28562-28563. T-5: 1 molde externo dorsal, DPO 28564. T-6: 1 molde externo dorsal, DPO 28565. T-V21: 1 molde interno ventral, 1 molde externo dorsal, DPO 111896 111897. G-1: 1 molde externo ventral, DPO 28566. C-4: 1 molde externo dorsal, DPO 28567. E-5: 1 molde externo dorsal, 2 moldes internos ventrales, DPO 28568-28470.

\section{Rugosochonetes sp.}

Fig. 5 e-h

\section{Material}

Tu-1: 1 valva ventral parcialmente desconchada y parte del molde interno ventral, 1 valva ventral y su molde externo, 1 molde externo dorsal y molde externo ventral, 4 valvas ventrales parcialmente desconchadas y 2 moldes externos ventrales, DPO 28909-28918.

\section{Descripción}

Concha de pequeño tamaño (L: 3-4,5 mm, A: 9-14 mm), muy transversa, contorno subrectangular con la máxima anchura en la charnela, formando las extremidades cardinales un ángulo de 75 grados. La relación L/A $=1 / 3$.

Valva ventral muy convexa, con la máxima convexidad en la mitad de la longitud de la valva. Orejetas grandes y apuntadas, no muy separadas del resto de la valva. Seno ausente.

Valva dorsal cóncava, ajustándose a la curvatura de la valva ventral. Pliegue ausente.

Ornamentación de ambas valvas a base de costillas, que se bifurcan hasta alcanzar una densidad de 8 en $2 \mathrm{~mm}$ en la región anterior de la valva.

Interior ventral con septo medio fino y corto cuya longitud es $1 / 5$ de la longitud de la valva.

\section{Discusión y comparaciones}

Las características distintivas de esta forma son la acusada curvatura de la concha, con la máxima convexidad en la mitad de la longitud de la valva, y su relación $\mathrm{L} / \mathrm{A}=1 / 3$. Estos caracteres hacen a Rugosochonetes sp, diferente de las demás especies de Rugosochonetes descritas en este trabajo, salvo $R$. cf. skipseyi, de la que se diferencia porque tiene un contorno más subtrapezoidal, y porque su máxima convexidad está en la región umbonal. También se diferencia de $R$. cf. latesinuatus y $R$. aff. latesinuatus, por no tener seno y pliegue.

\section{Distribución}

Procede de los paquetes Llanón o Tendeyón (Kashiriense?-Podolskiense?).

\section{Chonetinella Ramsbottom, 1952}

Especie tipo: Chonetes flemingi Norwood y Pratten, 1855.

\section{Chonetinella crassiradiata \\ (Dunbar y Condra,1932)}

* 1932 Chonetina flemingi var. crassiradiata Dunbar y Condra n. var., p. 157, lám. 19, figs. 37- 40.

.1968 Chonetinella flemingi crassiradiata (Dunbar y Condra, 1932); Winkler Prins, p. 119, lám. 9, figs. 9-10.

v.1979 Chonetinella crassiradiata (Dunbar y Condra, 1932); Martínez Chacón, p. 103, lám. 9, figs. 7-11.

v.1988 Chonetinella crassiradiata (Dunbar y Condra, 1932); Río García y Martínez Chacón, fig. 4-h.

\section{Material}

R-1: 1 molde externo dorsal, DPO 28578. T-2: 2 moldes externos ventrales, 1 molde interno ventral, 1 molde externo dorsal, DPO 111902-111905. T-4: 1 exterior ventral, DPO 28579. T-V21: 1 fragmento de molde interno ventral, DPO 28580. T-6: 1 molde dorsal interno y externo, DPO 28581.

\section{Chonetinella aff. flemingi (Norwood y Pratten,1855) \\ Fig. 6 a-c}

v.1988 Chonetinella aff. flemingi (Norwood y Pratten, 1855); Río García y Martínez Chacón; p. 40, fig. 4n.

\section{Material}

T-3: moldes interno ventral y externo dorsal, DPO 111910. 1 molde ventral interno y externo, DPO 28582. T-4: 3 moldes externos dorsales, DPO 28583-28585.

\section{Chonetinella cf. plebeia \\ (Dunbar y Condra,1932) \\ Fig. 6 d-e}

\section{Material}

S-1: 2 valvas ventrales, DPO 28586-28587. T-2: 1 molde externo dorsal, DPO 28588.

\section{Discusión y comparaciones}

Nuestro material es muy similar a Ch. plebeia (Dunbar y Condra,1932), por su forma, contorno y características de seno y pliegue; sin embargo, el material es escaso, y el tamaño de la concha es algo menor, por lo que la atribución se hace con reservas.

Se diferencia de Ch. crassiradiata por su menor tamaño, contorno más redondeado, menor convexidad y tener el seno menos marcado; de $C h$. aff. flemingi por su menor convexidad, no tener las orejetas tan abruptamente separadas del disco visceral, y su seno más suave. 
Figura 6. a-c. Chonetinella aff. flemingi (Norwood y Pratten, 1852). Todos los ejemplares proceden de la localidad T-3. a: moldes interno ventral y externo dorsal (x3). DPO 111910. b-c: molde interno ventral en vistas ventral y posterior ( $\mathrm{x} 3$ ). DPO 28582. d-e. Chonetinella cf. plebeia (Dunbar y Condra, 1932)). d: vista ventral (x4). DPO 28587. Localidad S-1. e: vista ventral (x4). DPO 28586. Localidad S-1. f-j. Chonetinella globosa n. sp. Todos los ejemplares proceden de la localidad A-3. f-h: Holotipo. Molde interno ventral en vistas ventral, posterior y lateral (x3). DPO 28893. i: Paratipo. Molde interno ventral (x3). DPO 28895. j: Paratipo. Molde interno ventral (x3). DPO 28894. k: Chonetinella sp. Molde externo dorsal (x3). DPO 28589. Localidad C-7. l-o. Neochonetes (Neochonetes) babianus Martínez Chacón y Winkler Prins, 2000. l-m: valva ventral en vistas ventral y lateral (x1,5). DPO 28540. Localidad S-1. n: molde interno dorsal (x2). DPO 28552. Localidad S-3. $\tilde{\mathbf{n}}$ : molde externo dorsal (x2). DPO 28553. Localidad S-3. o: molde interno ventral (x2). DPO 111891. Localidad T-3.

a-c. Chonetinella aff. flemingi (Norwood y Pratten, 1852). Locality T-3. a: internal mould of ventral valve and external mould of dorsal valve (x3). DPO 111910. b-c: internal mould of ventral valve in ventral and posterior views (x3). DPO
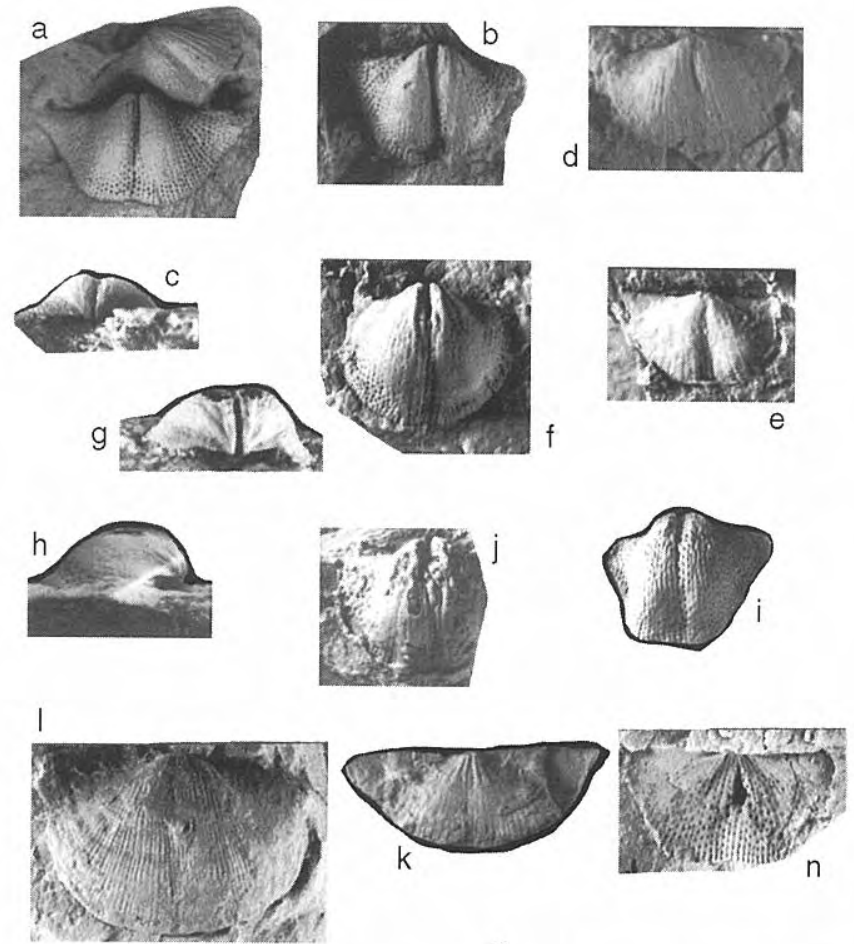

$\tilde{n}$
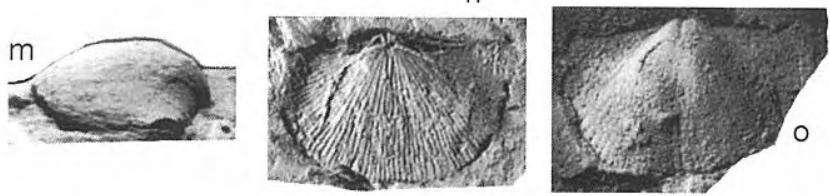
28582. d-e. Chonetinella $c f$. plebeia (Dunbar and Condra, 1932). d: ventral view (x4). DPO 28587. Locality S-1. e: ventral view (x4). DPO 28586. Locality S-1. f-j. Chonetinella globosa $n$. sp. Locality A-3. $\boldsymbol{f}$-h: Holotype. Internal mould of ventral valve in ventral, posterior and lateral views (x3). DPO 28893. $i$ : Paratype. Internal mould of ventral valve (x3). DPO 28895. $j$ : Paratype. Internal mould of ventral valve (x3). DPO 28894. $k$. Chonetinella sp. External mould of dorsal valve (x3). DPO 28589. Localidad C-7. l-o. Neochonetes (Neochonetes) babianus Martínez Chacón and Winkler Prins, 2000. l-m: ventral valve in ventral and lateral views (x1.5). DPO 28540. Locality S-1. c: internal mould of dorsal valve (x2). DPO 28552. Locality S-3. n: external mould of dorsal valve (x2). DPO 28553. Locality S-3. $\tilde{n}$ : internal mould of ventral valve (x2). DPO 111891. Locality T-3.

\section{Distribución}

Procede de la parte inferior del Paquete Levinco (Vereyense). Ch. plebeia se conoce del Pensilvaniense (Missouriense) del Centro y Este de Norteamérica (Sturgeon y Hoare,1968). Ch. cf. plebeia se ha descrito también en la Cordillera Cantábrica, en materiales vereyenses (Martínez Chacón,1990).

\section{Chonetinella globosa n. sp.} Fig. $6 \mathrm{f}-\mathrm{j}$

Derivatio nominis: Alude a la forma globosa de la valva ventral.

\section{Material}

Holotipo: molde ventral interno y externo, DPO 28893. Paratipos: moldes internos ventrales, DPO 28894-28895; molde interno ventral incompleto, DPO 28896.

\section{Estrato y localidad típicos}

Lutitas carbonatadas gris claro a techo de una banda calcárea, al lado de una fuente, en la pista que sale de Acebal (Laviana) hacia el SE. Yacimiento A-3, parte inferior del Paquete Levinco (Vereyense).

\section{Diagnosis}

Chonetinella de pequeño tamaño, muy concavoconvexa, de contorno subcircular. Seno estrecho, poco profundo, y constante en profundidad y anchura a lo largo de la longitud de la valva.

Small Chonetinella, strongly concavo-convex, and sub-circular in outline. Sulcus is narrow, moderately deep, with the width and depth constant along the surface of the shell.

\section{Descripción}

Concha de pequeño tamaño (L: 3-4,5 mm, A: 5-8 mm), de contorno subcircular y con la máxima anchura en la charnela. Estructura de la concha pseudopuntuada. 
Valva ventral muy convexa, con el ápice curvándose por detrás de una baja interárea. Disco visceral hinchado, que se separa suavemente de unas orejetas pequeñas y aplanadas. A cada lado del umbo se observan, al menos, 5 espinas cardinales que forman un ángulo de 30 grados con la charnela. Un seno recorre la valva; es estrecho, no muy profundo y mantiene constantes estos caracteres a lo largo de toda la longitud de la valva.

Ornamentación con costillas, que aumentan en número por intercalación, alcanzando en la región anterior una densidad de 10 en $2 \mathrm{~mm}$.

Interior ventral con un alto y fuerte septo medio que se va haciendo más bajo y delgado hacia la región anterior, hasta acabar como una cresta media, que se prolonga $2 / 5$ de la longitud de la valva, coincidiendo su fin con el límite anterior de los músculos aductores. Las huellas de estos últimos son alargadas y estrechas, con una forma apuntada en la región posterior, ensanchándose y adoptando una forma redondeada en la anterior.

Superficie interna fuertemente papilosa, con las papilas en filas radiales.

\section{Discusión}

Las características de la valva ventral: contorno subcircular, muy convexa (globosa), y seno muy estrecho y constante en profundidad y anchura, la diferencian de las otras especies de Chonetinella, por lo que, a pesar de no conocerse valvas dorsales, parece justificada la creación de una nueva especie.

\section{Comparaciones}

Es comparable a Ch. makovi Aisenverg,1985 y Ch. jeffordsi Stevens, 1962, por su seno estrecho y constante en anchura y profundidad. Se separa de ambas por ser más globosa y tener un contorno más circular. Además, la nueva especie es comparable a algunas formas citadas en la Cordillera Cantábrica que tienen un seno profundo, estrecho y constante, tales como $C h$. ex gr. verneuiliana (Norwod y Pratten,1855), en Martínez Chacón (1990), de la que se diferencia por tener el disco visceral más hinchado, siendo la separación entre este y las orejetas menos abrupta; Chonetinella sp., en Martínez Chacón y Winkler Prins (1985a), de la que se distingue por su contorno más subcircular. Además, se diferencia de $C h$. crassiradiata, Ch. aff. flemingi y Ch. cf. plebeia por su disco visceral hinchado, seno estrecho, constante y profundo. Además, de las dos primeras, lo hace también por su contorno redondeado.

Como ya se mencionó anteriormente en la descripción de Globosochonetes? merayoi n. sp , el tamaño de la valva, así como la presencia de seno y pliegue, aproximan a ambas formas. Se diferencian por el contorno subcircular, costillas más anchas, septo medio ventral más largo, así como el seno y pliegue más profundos de Ch. globosa n. sp.

\footnotetext{
Distribución

Procede de la parte inferior del Paquete Levinco (Vereyense).
}

\section{Chonetinella $\mathrm{sp}$ \\ Fig. $6 \mathrm{k}$}

\section{Material}

C-7: 1 molde dorsal interno y externo, DPO 28589.

\section{Discusión y comparaciones}

La forma, tamaño, desarrollo de seno y pliegue, y el proceso cardinal bilobado corresponden a los de Chonetinella. La escasez de material y su mal estado de conservación hace que la atribución no sea más precisa. Hay que hacer notar, sin embargo, que este material es muy similar al descrito por Martínez Chacón (1979; p. 103, lám. 9, fig. 11), como Ch. crassiradiata.

\section{Distribución}

Procede del Paquete Tendeyón (Podolskiense).

$$
\text { Neochonetes (Neochonetes) Muir-Wood, } 1962
$$

Especie tipo: Chonetes dominus King, 1938.

\section{Neochonetes (Neochonetes) babianus Martínez Chacón y Winkler Prins, 2000}

Fig. 6 1-o

1968 Neochonetes acanthophorus (Girty,1934); Winkler Prins, p. 119, lám. 9, figs. 11-16,18.

v.1979 Rugosochonetes acanthophorus (Girty,1934); Martínez Chacón, p. 91; lám. 7, figs. 19-22; lám. 8, figs. 1-9.

v.1985b Rugosochonetes acanthophorus (Girty,1934); Martínez Chacón y Winkler Prins, p. 236, pl. I, figs. 1-2.

v.1988 Rugosochonetes cf. acanthophorus (Girty,1934), Río García y Martínez Chacón; fig. 4-c.

v.1990 Rugosochonetes acanthophorus (Girty,1934); Martínez Chacón, p. 96, lám. I, fig. 19.

2000 Neochonetes (Neochonetes) babianus sp. nov; Martínez Chacón and Winkler Prins, p. 226.

\section{Material}

S-1: 1 valva ventral y molde externo ventral, 1 ejemplar completo, 5 valvas ventrales parcialmente conservadas, 1 molde externo ventral, DPO 28538-28545. S-3: 1 molde interno dorsal y su molde externo dorsal, 1 molde externo dorsal y molde externo ventral, DPO 28552-28553. T-2: 1 valva ventral y molde externo ventral, 3 valvas ventrales, DPO 28546-28549. T-3: 4 moldes externos dorsales, 1 molde externo ventral, y 1 molde interno ventral, DPO 111890-111895. G-1: 1 molde externo ventral, 1 molde interno ventral y su molde externo, DPO 28550-28551.

\section{Discusión}

Este material había sido identificado en trabajos anteriores (Río García, 1986, Río García y Martínez Chacón,1988 y Río García, 1993), como Rugosochonetes acanthophorus y $R$. cf. acanthophorus, asignando a este último, el material procedente de G-1, T-3 y S-3. 

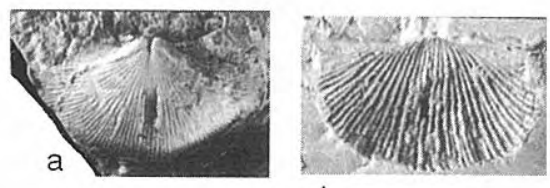

d

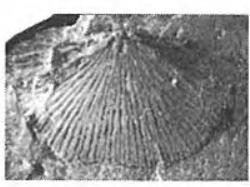

e

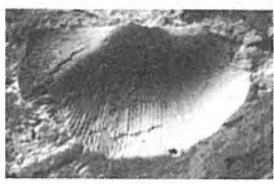

b
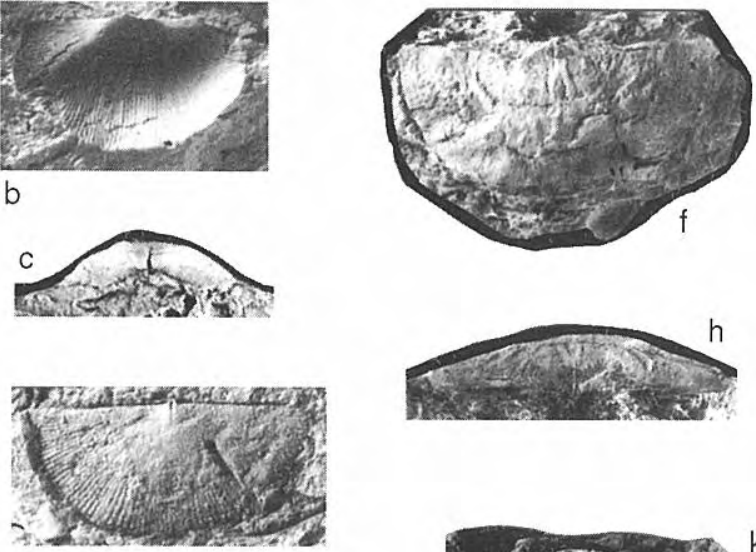

g
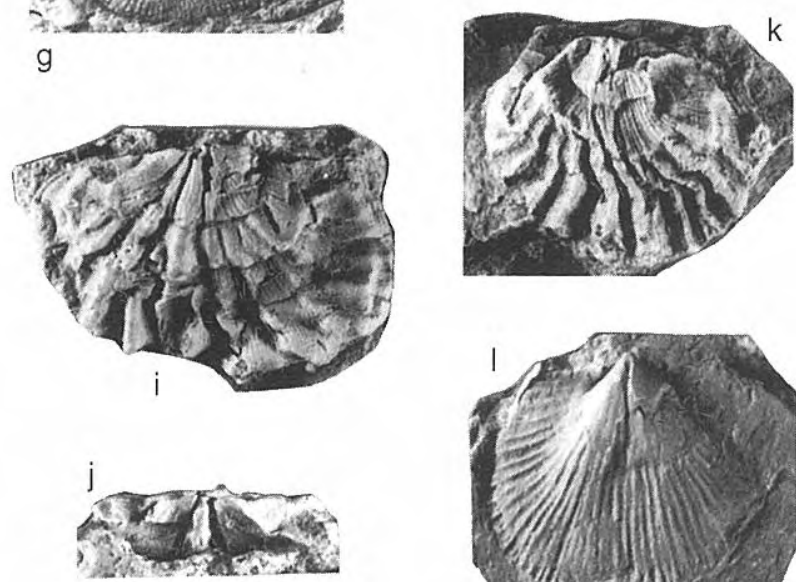

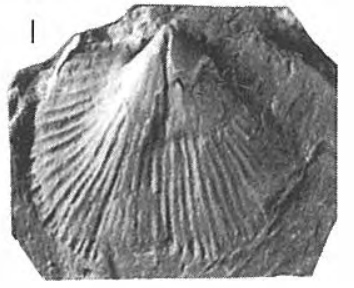

Posteriormente, Martínez Chacón y Winkler Prins (2000), establecen la nueva especie Neochonetes (Neochonetes) babianus para un material de la Cordillera Cantábrica que previamente había sido identificado como Neochonetes acanthophorus (Girty, 1934) o como Rugosochonetes acanthophorus, diferenciándolo de $N$. (Neochonetes) acanthophorus, por su costulación más pronunciada, que no se vuelve obsoleta en el margen anterior, y utilizando para su inclusión en Neochonetes (Neochonetes) el criterio de separación entre Neochonetes y Rugosochonetes que indican Archbold (1981) y Racheboeuf (1998): el desarrollo de un par de crestas vasculares en el interior ventral de Neochonetes, que están ausentes, o muy débilmente desarrolladas en Rugosochonetes.

En este trabajo se incluye el material previamente identificado como $R$. acanthophorus, en $N$. (Neochonetes) babianus por ser idéntico al atribuido previamente por Martínez Chacón (1979) a $R$. acanthophorus. Asimismo, el material previamente identificado como $R$. cf. acanthophorus (Fig. 6 n-o) se incluye también porque a pesar de presentar algunas diferencias con respecto al previamente identificado como $R$. acanthophorus: valva ventral algo menos
Figura 7. a-c. Isochonetes? sp.1. Moldes ventrales interno, externo y vista posterior del molde interno (x2). DPO 28577. Localidad T-3. d-e. Isochonetes? sp. 2. d: molde externo ventral (x2). DPO 28574. Localidad G-2. e: molde externo dorsal (x2). DPO 28576. Localidad T-4. f. Sokolskia sp.1. Molde interno ventral (x2,5). DPO 28590. Localidad T-6. g-h. Sokolskia sp. 2. Molde interno ventral en vistas ventral y posterior (x1,5). DPO 28591 . Localidad T-2. i-k. Meekella cf. eximia (Verneuil, 1845). Todos los ejemplares proceden de la localidad E-3. i-j: molde interno ventral en vistas ventral y posterior $(\mathrm{x} 1,5)$. DPO 28514. $\mathrm{k}$ : molde interno ventral (x2). DPO 28515. 1. Schuchertella cf. gibba Manankov, 1979. Molde interno dorsal $(x 1,5)$. DPO 28534. Localidad E-5.

$a-c$. Isochonetes? sp.1. Internal and external ventral moulds and posterior view of the internal mould (x2). DPO 28577. Locality T-3. d-e. Isochonetes? sp. 2. d: external ventral mould ( $x 2)$. DPO 28574. Locality G-2. e: external dorsal mould (x2). DPO 28576. Locality T-4. $f$. Sokolskia sp.1. Internal ventral mould (x2.5). DPO 28590. Locality T-6. $\boldsymbol{g}$-h. Sokolskia sp. 2. Internal ventral moulds in ventral and posterior views (x1.5). DPO 28591. Locality T-2. $\boldsymbol{i}-\boldsymbol{k}$. Meekella $c f$. eximia (Verneuil, 1845). Locality E3. $i-j$ : internal mould of ventral valve in ventral and posterior views (x1.5). DPO 28514. $k$ : internal mould of ventral valve $(x 2)$. DPO 28515. l. Schuchertella $c f$. gibba Manankov, 1979. Internal mould of dorsal valve (x1.5). DPO 28534. Locality E-5.

convexa, máxima anchura en la charnela y costillas algo más finas, con la diagnosis de $N$. (N.) babianus, ambas formas pueden quedar incluidas en esta especie.

\section{Comparaciones}

Se diferencia de $N$. (Neochonetes) acanthophorus, al que previamente se había asignado este material, por sus pronunciadas costillas, que no se vuelven obsoletas hacia el margen anterior.

\section{Distribución}

Procede de la parte inferior del Paquete Levinco (Vereyense). La especie se conoce en la Cordillera Cantábrica, en materiales de edad Bashkiriense-Vereyense.

\section{Isochonetes Aisenverg, 1985}

Especie tipo: Isochonetes larinoensis Aisenverg, 1985.

\section{Isochonetes? sp. 1}

Fig. 7 a-c

\section{Material}

T-3: 1 molde ventral externo e interno, DPO 28577. 


\section{Descripción}

Valva ventral de talla media (L: $7 \mathrm{~mm}, \mathrm{~A}: 12 \mathrm{~mm}$ ), fuerte y regularmente convexa, con orejetas pequeñas y aplanadas. Gancho curvándose por detrás de la interárea. Máxima anchura próxima a la charnela, con las extremidades cardinales bastante rectas. Contorno subelíptico. Seno ausente.

Ornamentación a base de finas costillas, que se intercalan y bifurcan alcanzando en el frente una densidad de 10 en 2 $\mathrm{mm}$.

Interior ventral con un alto y corto septo medio que se prolonga $1 / 5$ de la longitud de la valva.

\section{Discusión}

Los caracteres internos y externos, como la convexidad regular y ausencia de seno en la valva ventral, aproximan este material a Isochonetes. Sin embargo, la escasez de material hace que la asignación a este género se haga con reservas. Se trataría de la $1^{\text {a }}$ cita de Isochonetes en la Cordillera Cantábrica.

\section{Distribución}

Procede de la parte baja del Paquete Levinco (Vereyense). Isochonetes se conoce del Bashkiriense Inferior de Ucrania.

\section{Isochonetes? sp. 2}

Fig. 7 d-e

\section{Material}

G-2: 1 molde externo ventral y dorsal, DPO 28574. T-4: 2 moldes externos ventrales y dorsales, DPO 28575-28576.

\section{Discusión y comparaciones}

Al igual que en el caso anterior, la convexidad tan regular de la valva ventral, así como la ausencia de seno, son características de Isochonetes. No obstante, la escasez de material hace que se tengan ciertas reservas en la atribución genérica. Se diferencia de Isochonetes? sp. 1 , por sus costillas más gruesas y menor convexidad.

\section{Distribución}

Procede del Paquete Levinco (Vereyense-Kashiriense).

Sokolskia Aisenverg,1980

Especie tipo: Sokolskya calmiusensis Aisenverg, 1980.

\section{Sokolskya sp. 1}

Fig. $7 \mathrm{f}$

v.1979 Megachonetes (?) cf. zimmermanni (Paeckelmann, 1930); Martínez Chacón, p. 114, lám. 11, figs. 2-3.

\section{Material}

T-6: 1 molde interno ventral y 1 fragmento de molde interno dorsal, DPO 28590.

\section{Descripción}

Concha de tamaño medio ( $\mathrm{L}: 9 \mathrm{~mm}, \mathrm{~A}: 21 \mathrm{~mm}$ ), suavemente concavoconvexa, charnela igual o muy próxima al valor de la anchura, con las extremidades cardinales casi rectas. Comisura frontal rectimarginada.

Valva ventral poco y regularmente convexa, con la máxima convexidad en el centro de la valva, no existiendo una gran diferenciación con las orejetas, que son grandes y aplanadas. Interárea no muy alta. A cada lado del umbo se disponen, al menos, 3 bases de espinas, sin poder precisar el ángulo que forman respecto de la charnela.

Valva dorsal muy poco cóncava, ajustándose a la ventral.

Ornamentación a base de costillas muy finas (unas 10 en $2 \mathrm{~mm}$ ), cruzadas por arrugas concéntricas, dispuestas de una manera irregular.

Interior ventral con septo medio bajo y delgado, que se prolonga hasta $1 / 3$ de la longitud de la valva.

Interior dorsal con septo medio bajo y más fuerte que el ventral, que llega hasta la mitad de la longitud de la valva.

Superficie interna de ambas valvas muy papilosa, con filas radiales de papilas.

\section{Discusión y comparaciones}

La forma, curvatura de la valva ventral y ornamentación, así como su interior, aproximan este material a Sokolskia, no pudiendo precisar más, por el poco material del que se dispone. Sokolskya sp.1 se diferencia de la especie tipo del género, $S$. calmiusensis, por ser de menor tamaño y tener las extremidades cardinales más rectas.

\section{Distribución}

Procede del Paquete Llanón (Kashiriense). El género se conoce del Bashkiriense de la cuenca del Donetz (Ucrania) y del Serpukhoviense Superior-Bashkiriense Inferior de los Pirineos franceses (Legrand-Blain, 1983). En la Cordillera Cantábrica se conoce del Bashkiriense Sup.-Kasimoviense.

Megachonetes (?) cf. zimmermanni, descrita por Martínez Chacón (1979) en la Cordillera Cantábrica, procede de materiales de edad Bashkiriense Sup.Kashiriense.

\section{Sokolskya sp. 2}

Fig. $7 \mathrm{~g}-\mathrm{h}$

\section{Material}

T-2: 1 molde ventral interno y externo, DPO 28591.

\section{Comparaciones}

Se diferencia de Sokolskya sp. 1 por su menor tamaño y valva ventral mucho más plana.

ORDEN ORTHOTETIDA Waagen, 1884

SUBORDEN ORTHOTETIDINA Waagen, 1884

Superfamilia Orthotetoidea Waagen, 1884

Familia Meekellidae Stehli,1954

Subfamilia Meekellinae Stehli, 1954

Meekella White y St. John, 1867 
Especie tipo: Plicatula striatocosta Cox, 1857.

\section{Meekella cf. eximia (Verneuil,1845) \\ Fig. $7 \mathrm{i}-\mathrm{k}$}

\section{Material}

E-3: 8 moldes internos ventrales y parte de sus moldes externos, 1 molde interno dorsal, DPO 28514-28522. E-5: 1 molde interno ventral, DPO 28523.

\section{Descripción}

Concha de tamaño medio (L: 15-20 mm, A: 32-35 mm), biconvexa, transversa, y con la máxima anchura en la mitad de la longitud de la valva.

Valva ventral convexa, con interárea alta y triangular. Ornamentación a base de pliegues anchos y angulosos, que recorren toda la valva y van creciendo en anchura, contándose en el frente 4 en $10 \mathrm{~mm}$. Toda la valva está recorrida por finas capilas. Seno ausente.

Valva dorsal convexa y con una interárea muy alta. El resto de los caracteres son similares a los de la ventral.

Interior ventral con lamelas dentales muy finas, ligeramente divergentes entre sí (casi paralelas), y extendiéndose aproximadamente $1 / 3$ de la longitud de la valva.

Interior dorsal con crestas internas cortas, que forman entre sí un ángulo cercano a los 80 grados.

\section{Discusión y comparaciones}

Este material, si bien se aproxima a $M$. eximia, se hace con reservas por la mala conservación y escasez de los ejemplares de los que se dispone.

Esta especie es comparable a $M$. depressa Schellwien,1900 por su tamaño, altura de la interárea ventral y caracteres internos; sin embargo, se diferencia por la ornamentación, a base de costillas mucho más desarrolladas, y por ser más transversa. Se trataría de la $1^{\mathrm{a}}$ descripción de la especie en la Cordillera Cantábrica.

\section{Distribución}

Procede del Paquete Tendeyón (Podolskiense). En la Cordillera Cantábrica M. eximia ha sido citada por Mallada (1875), sin figurar, Barrois (1882), sin describir ni figurar, y en el Westfaliense C superior-D inferior, por Winkler Prins (en Van Loon, 1971), sin describir. También se conoce del Carbonífero Medio-Pérmico inferior de Rusia (Manankov, 1979), Carbonífero Superior de China y Pirineos centrales franceses (Legraind-Blain, 1983).

Familia Schuchertellidae Williams, 1953

Subfamilia Schuchertellinae Williams, 1953 Schuchertella Girty, 1904

Especie tipo: Streptorhynchus lens White, 1862.

\section{Schuchertella sajakensis asturica Martínez Chacón,1979}

*v.1979 Schuchertella sajakensis asturica n. subsp.; Martínez Chacón, p. 71; lám. 4, figs. 16-21; lám. 5, figs. 1-5.

v.1988 Schuchertella sajakensis asturica Martínez Chacón, 1979; Río García y Martínez Chacón, fig. $4 a$.

\section{Material}

S-1: 2 moldes internos dorsales, DPO 28524-28525. T-2: 2 moldes internos ventrales, 5 moldes internos dorsales, 1 molde externo ventral, 1 molde externo dorsal, DPO 1702517033. T-3: 2 moldes internos dorsales, 1 molde externo dorsal, DPO 17034-17036. T-4: 1 molde interno ventral, 1 molde interno dorsal, 4 moldes externos dorsales, DPO 17037-17042. T-V21: 5 moldes internos dorsales, 4 moldes externos dorsales, DPO 17043-17051. T-6: 1 molde interno ventral, DPO 28526. A-2: 1 molde interno dorsal, DPO 28527. R-4: 1 molde dorsal interno y externo, DPO 28528. E-5: 4 moldes internos dorsales, 1 molde interno ventral, DPO 28529-28533.

\section{Schuchertella cf. gibba Manankov, 1979} Fig. 71

\section{Material}

E-5: 1 molde dorsal interno y externo, 1 molde externo ventral, 1 fragmento de molde externo, DPO 28534-28536.

\section{Descripción}

Concha de tamaño medio (L: 12-20 mm, A: 14-26 mm), ligeramente transversa y de contorno subcuadrado redondeado. Máxima anchura en la mitad de la longitud de la valva.

Valva ventral suavemente convexa. Interárea relativamente alta (hasta $4 \mathrm{~mm}$ ) y ligeramente apsaclina; pseudodeltidio ancho, triangular y convexo.

Valva dorsal ligeramente convexa y con una interárea muy baja. En la única valva dorsal encontrada, se observa una ligera depresión media.

Ornamentación a base de costillas fuertes y angulosas que aumentan en número por intercalación, contándose en la región anterior unas 8 en $5 \mathrm{~mm}$. Se observan sobre el techo de las costillas pequeñas proyecciones espiniformes dispuestas al tresbolillo, con una densidad de 8 en $2 \mathrm{~mm}$ en la región anterior. Además, toda la concha está recorrida por finas lamelas concéntricas de crecimiento.

Interior dorsal con crestas internas cortas y divergiendo poco de la charnela.

\section{Discusión y comparaciones}

Los caracteres internos y la mayoría de los externos coinciden con los de $S$. gibba, sin embargo, el menor tamaño de la concha y la escasez de material hacen que la atribución se haga con ciertas reservas. Se diferencia de S. sajakensis asturica Martínez Chacón, 1979, por su 
contorno subcuadrado y por la distinta ornamentación, ya que $S$. cf. gibba tiene costillas fuertes entre las que se intercalan otras del mismo grosor.

\section{Distribución}

S. gibba no se había citado hasta ahora en la Cordillera Cantábrica. En este trabajo procede del Paquete Tendeyón (Podolskiense). S. gibba se conoce del Carbonífero MedioSuperior de Siberia y el Ártico (Manankov, 1979).

\section{AGRADECIMIENTOS}

Quisiera expresar mi agradecimiento a la Dra. $M^{\mathrm{a}}$ Luisa Martínez Chacón por su constante ayuda durante la realización de este trabajo. También a los Drs. M. LegrandBlain y C. Winkler Prins, que, como revisores, han enriquecido notablemente el manuscrito final.

\section{BIBLIOGRAFÍA}

Afanasjeva, G. A. 1984. Brachiopod systematics of the family Anopliidae. Palaeontological Journal, 1, 89-93.

Aisenverg, D. E. 1980. Novye rannebashkirskiye khonetidy Doneskogo basseyna. Paleontologischeskii Zhurnal, 3, 52-57, pl. 9.

Aisenverg, D.E. 1985. Novye khonetidy iz carbona Donbassa. Paleontologicheskii Zhurnal, 4, 35-42, pl. 4.

Almela, A. y Ríos, J.M. 1953. Datos para el conocimiento de la Geología asturiana (valles de Riosa y Proaza). Boletín Instituto Geológico Minero España, 65, 34 pp., 3 láms.

Aller, J.A. 1986. La estructura del sector meridional de las unidades del Aramo y Cuenca Central de Asturias. Servicio de Publicaciones del Principado de Asturias. Consejería de Industria y Comercio, $180 \mathrm{pp}$.

Amerom, H.W.J. Van, Bless, M.J.M. and Winkler Prins, C:F. 1970. Some paleontological and stratigraphical aspects of the Upper Carboniferous Sama Formation (Asturias, Spain). Mededelingen Rijks Geologische Dienst, N.S., 21, 9-79, 10 láms., 1 encl.

Archbold, N.W. 1980. Studies on Western Australian Permian brachiopods, 1. The family Anopliidae (Chonetidina). Proceedings of the Royal Society of Victoria, 91 (2), 181-192.

Archbold, N.W. 1981. Studies on Western Australian Permian brachiopods. 2. The family Rugosochonetidae Muir-Wood, 1962. Proceedings of the Royal Society of Victoria, 93 (2), 109-128.

Barba, P. 1991. Estratigrafía y sedimentología de la sucesión westfaliense del borde SE de la Cuenca Carbonífera Central. Tesis Doctoral (inédita), Departamento de Geología, Universidad de Oviedo, 237 pp.

Barba P., Heredia N. y Villa E. 1991. Estratigrafía y edad del Grupo Lena en el sector de Lois-Ciguera (Cuenca Carbonífera Central, NO de España). Revista de la Sociedad Geológica de España, 4, 61-77.

Barrois, Ch. 1882. Recherches sur les terrains anciens des Asturies et de la Galice. Mémoire de la Société Géologique du Nord, 2 (1), 630 pp., 20 láms.
Boucot A.J. and Harper C.W. 1968. Silurian to Middle Devonian Chonetacea. Journal of Paleontology, 42, 143176.

Brunton, C.H.C. 1968. Silicified brachiopods from the Visean of County Fermanagh (II). Bulletin British Museum (Natural History), London, 16 (1), 1-70, láms. $1-9$.

Caride, C. y García Loygorri, A. 1968. Estratigrafía del Carbonífero Productivo de Riosa (Asturias). III Jornadas Nacionales Minero-Metalúrgicas. Gijón 1967, 1, 865923, 6 láms.

Caride, C., Gervilla, M., Ortuño, G. y Velando F. 1973. Mapa geológico de España, E 1:50.000, Hoja de Mieres, $2^{a}$ serie, $1^{\text {a }}$ ed. Instituto Geológico y Minero de España, Madrid.

Casillas, F. 1984. Estudio estratigráfico de la serie westfaliense del valle del Río Negro (Aller). Tesis Licenciatura (inédita), Departamento Estratigrafía, Universidad Oviedo, 68 pp.

Comte, P. 1959. Recherches sur les terrains anciens de la Cordillère Cantabrique. Memorias del Instituto Geológico y Minero de España, 60, 1-440.

Cox, E. T. 1857. A description of some of the most characteristic shells of the principal coal seams in the western basin of Kentucky. Geological Survey of Kentucky Report, 3, 557-576, pl. 8-10.

Currie, E.D., Duncan, C. and Muir-Wood, H.M. 1937. The fauna of Skipsey's Marine Band. Transactions of the Geological Society of Glasgow, 413, 413-452, pls. 2-4.

Delépine, G. 1943. Les faunes marines du Carbonifère des Asturies (Espagne). Mémoires de l'Académie des Sciences de l'Institut de France, 66 (3), 1-122, 6 láms.

Demanet, F. 1943. Les horizons marins du Westphalien de la Belgique et leurs faunes. Memoirs Musée Royal D'Histoire Naturel de Belgique, 101, 1-164, láms. 106144.

Demanet, F. 1949. Contribution á l'étude de la microfaune marine du Westphalien de la Campine. Bulletin de l' Institute Royal Sciences Naturelles de Belgique, 25/37, 1-16.

Demanet, F. et Straelen, V. Van 1938. Faune houillière de la Belgique. In: Renier, A., Stockmans, F., Demanet, F. et Straelen, V. van. Flore et faune houilliêres de la Belgique. Patrimoine du Musée Royal d’Histoire Naturelle de Belgique, Bruxelles, 99-246, pls. 106-144.

Dunbar, C.O. and Condra, G.E. 1932. Brachiopoda of the Pennsylvanian system in Nebraska. Nebraska Geological Survey, 5, 1-377, 44 pl.

Feys, R., García-Loygorri, A. et Ortuño, G. 1974. Stratigraphie des faisceaux productifs du Bassin Central des Asturies (Espagne). Compte Rendu VII Congrès International de Stratigraphie et de Géologie du Carbonifère, Krefeld 1971, 3, 27-44.

García-Loygorri, A. 1974. Caractères généraux du Bassin Central des Asturies (Espagne). Compte Rendu VII Congrès International de Stratigraphie et de Geologie du Carbonifère, Krefeld 1971, 3, 111-127.

García-Loygorri, A., Ortuño, G., Caride de Liñán, C., Gervilla, M., Greber, H. y Feys, R. 1971. El Carbonífero de la Cuenca Central Asturiana. Trabajos de Geología Universidad de Oviedo, 3, 101-150. 
Girty, G.H. 1904. New molluscan genera from the Carboniferous. U.S. Natural Museum, Proceedings, 27, 721-736, pls. 16-18.

Girty, G.H. 1934. Pleurotomaria pseudostrigillata nom. nov. and Chonetes acanthophorus nom. nov. Journal of the Washington Academy of Sciences, 24, 541.

Granados, L.F., Solovieva, M.N., Reitlinger, C.A., and Martínez Díaz, C. 1985. The Bashkirian-Moscovian boundary problem in the Asturias (Northwest Spain). Compte Rendu X Congrès International de Stratigraphie et de Géologie du Carbonifère, Madrid, 1, 27-34.

Grand, A. 1874. Etude sur le bassin houiller des Asturies (Espagne). Contribution géologique. Mode d'exploitation. Voies de comunication. E. Lacroix, Viebille et Capiomont, Paris, 1-64.

Hanger R. A. and Strong E. E. 2000. Phylogeny of the Anopliidae (Brachiopoda: Chonetidina). Historical Biology, 14, 285-298.

Kaesler, R.L. (Ed.) 2000. Treatise on Invertebrate Paleontology. Part H. Brachiopoda (revised). Geological Society of America and the University of Kansas, 2, 1423; 3, 423-919.

Julivert, M. 1971. Decollement tectonics in the Hercynian Cordillera of NW Spain. American Journal of Science, 270, 1-29.

King, R.H. 1938. New Chonetidae and Productidae from Pennsylvanian and Permian strata of north-central Texas. Journal of Paleontology, 12, 257-279.

Legrand-Blain, M., 1983. Brachiopodes carbonifères des Pyrenees centrales francaises. Geobios, 16, 285-327.

Leyva, F. y Gervilla, M. (Dirs.) 1983. El Carbonífero Medio de la Cuenca Central Asturiana y zonas adyacentes. Libro guía de la excursión W. X Congreso Internacional de Estratigrafía y Geología del Carbonífero, Madrid, 1983. E. N. Adaro de Investigaciones Mineras, Madrid, $200 \mathrm{pp}$

Loon, A.J. Van 1971. The stratigraphy of the Westphalian C around Prioro (prov. León. Spain). Trabajos de Geología, Universidad de Oviedo, 3, 231-266.

Luque, C., Gervilla, M., Sáenz de Santa María, J.A., Leyva, F., Laveine, J.P., Loboziak, S. y Martínez Chacón, M.L. 1985. Características sedimentológicas y paleontológicas de los paquetes productivos en el corte de La InvernizaEl Cabo (Cuenca Central Asturiana). Compte Rendu X Congrès International de Stratigraphie et de Géologie du Carbonifère, Madrid, 1983, 1, 281-302.

Mallada, L. 1875. Sinopsis de las especies fósiles que se han encontrado en España. Boletín de la Comisión del Mapa Geológico de España, 2: 1-160, 7 láms. (Siluriano), 1: 48, 13-14 (Devoniano), 1-3, 6-11 (Carbonífero).

Mallada, L. 1892. Catálogo general de las especies fósiles encontradas en España. Boletín de la Comisión del Mapa Geológico de España, 18, 253 pp.

Manankov, I.N. 1979. Strofomenidy pozdnego paleozoya Sibiri i Artiki (Late Paleozoic Strphomenidis from Siberia and The Artic). Akademiya Nauk SSSR, Trudy Paleontologicheskogo Instituta Izdat "Nauka", 171, $102 \mathrm{pp}$.

Martínez Álvarez, J.A. 1962. Estudio geológico del reborde oriental de la Cuenca Carbonífera Central de Asturias.
Instituto de Estudios Asturianos, Diputación Provincial de Oviedo, 229 pp.

Martínez Chacón, M.L. 1979. Braquiópodos carboníferos de la Cordillera Cantábrica (Orthida, Strophomenida y Rhynchonellida). Memorias del Instituto Geológico y Minero de España, 96, 291 pp., 32 láms.

Martínez Chacón, M.L. 1990. Braquiópodos carboníferos de la costa E de Asturias (España). I: Orthida, Strophomenida, Rhynchonellida y Athyridida. Revista Española de Paleontología, 5, 91-110.

Martínez Chacón, M.L. y Río García, L.M. 1987. Cantabriella, nuevo género de Syringothyridacea (Brachiopoda) del Carbonífero Cantábrico (N de España). Revista Española de Paleontología, 2, 19-26.

Martínez Chacón, M.L. and Winkler Prins, C.F. 1977. A Namurian brachiopod fauna from Meré (Province of Oviedo, Spain). Scripta Geologica, 39, 1-67, 14 láms.

Martínez Chacón, M.L. and Winkler Prins, C.F. 1985a. Upper Carboniferous (Kasimovian) brachiopods from Asturias (N of Spain). Compte Rendu X Congrès International de Stratigraphie et de Géologie du Carbonifère, Madrid, 1983, 2, 435-448.

Martínez Chacón, M.L. and Winkler Prins, C.F. 1985b. The brachiopod fauna of the San Emiliano Formation (Cantabrian Mountains, NW Spain) and its connection with other areas. Compte Rendu IX Congrès International de Stratigraphie et de Géologie du Carbonifère, Washington and Champaign-Urbana, 1979, 5, 233-244.

Martínez Chacón, M.L. and Winkler Prins, C.F. 2000. New Rugosochonetidae (Brachiopoda) from the upper Bashkirian and Moscovian of the Cantabrian Mountains (N Spain). Revista Española de Paleontología, 15, 219-232.

Martínez Díaz, C., Granados, L.F., Leyva, F., Laveine, J.P., Solovieva, M.N., Reitlinger, E.A., Gervilla, M., Loboziak, S., Brousmiche, C., Candilier, A.M., Pendas, F. y Horvath, V. 1985. Aportaciones a la cronoestratigrafía del Carbonífero Medio de Asturias, y nuevos datos para un intento de correlación de las escalas marinas y continentales. Compte Rendu X Congrès International de Stratigraphie et de Géologie du Carbonifère, Madrid, 1, 269-280.

McCoy, F. 1855. Systematic descriptions of the British Palaeozoic fossils in the Geological Museum of the University of Cambridge, 3, 407-661.

Muir-Wood, H.M. 1962. On the morphology and classification of the brachiopod suborder Chonetoidea. British Museum (Natural History), London, 124 pp., 16 láms.

Norwood, J.G. and Pratten, H. 1855. Notice of the genus Chonetes as found in the western states and territories, with descriptions of eleven new species. Academy Natural Sciences, Philadelphia, Journal, 3, 23-32, 2.

Paeckelmann, W. 1930. Die Brachiopoden des deutschen Unterkarbons. 1. Teil: Die Orthiden, Strophomeniden und Choneten des Mittleren und Oberen Unterkarbons. Abhandlungen der Preussischen Geologisches Landesanstalt, 122, 145-326, láms. 9-24.

Patac, I. 1944. Relaciones estratigráficas entre varias cuencas hulleras de Europa (España, Bélgica, Holanda, Rusia). Boletín del Instituto Geológico y Minero de España, 56, 142 pp. 
Pérez Estaún, A., Bastida, F., Alonso, J.L., Marquínez, J., Aller, J., Álvarez-Marrón, J., Marcos, A. and Pulgar, J.A. 1988. A thin-skinned tectonics model for an arcuate fold and thrust belt: The Cantabrian zone. Tectonics, 7, 517537.

Phillips, J. 1841. Figures and descriptions of the Paleozoic fossils from Cornwall, Devon and West Somerset. Memoirs Geological Survey Great Britain, $231 \mathrm{pp}$.

Racheboeuf, P.R. 1998. The chonetoidean brachiopods. A revised and updated systematic and bibliographic catalogue. Documents des Laboratoires de Géologie Lyon, 148, 178 pp.

Ramsbottom, W.H.C. 1952. The fauna of the Cefn Coed Marine Band in the Coal Measures at Aberbaiden near Tordu, Glamorgan. Bulletin Geological Survey Great Britain, 4, 8-32, láms. 2-3.

Río García, L.M. 1986. Braquiópodos del Paquete Levinco en el corte de Villoria-Los Tornos (Cuenca Carbonífera Central Asturiana). Tesis Licenciatura, Departamento Paleontología Facultad Geología Universidad Oviedo, 106 pp., 3 láms. (inédita).

Río García, L.M. 1993. Braquiópodos de los Paquetes Improductivos de la Cuenca Carbonifera Central (Asturias, $N$ de España). Tesis Doctoral. Universidad de Oviedo, 260 pp., 9 lám. (inédita).

Río García, L.M. 1998. Asociaciones de braquiópodos moscovienses en los Paquetes Improductivos de la Cuenca Carbonífera Central de Asturias. Trabajos de Geología, Universidad de Oviedo, 20, 157-166.

Río García, L.M. y Martínez Chacón, M.L. 1988. Braquiópodos moscovienses del Paquete Levinco (Cuenca Carbonífera Central de Asturias). Trabajos de Geología, Universidad de Oviedo, 17, 33-56.

Rowell, A. J. 1967. A numerical taxonomic study of the chonetacean brachiopods. In: Essays in Paleontology and Stratigraphy (Eds. C. Teichert and E. L. Yochelson). University of Kansas Press, Lawrence, 113-140.

Sáenz de Santa María, J. A., Luque, C., Gervilla, M., Laveine, J.P., Loboziak, S., Brousmiche, C., Coquel, R. y Martínez Díaz, C. 1985. Aportación al conocimiento estratigráfico y sedimentológico del Carbonífero productivo de la Cuenca Central Asturiana. Compte Rendu X Congrès International de Stratigraphie et de Geologie du Carbonifère, Madrid, 1, 303-326.

Schellwien, E. 1892. Die Fauna des karnischen Fusulinenkalks. I. Theil. Geologische Einleitung und Brachiopoda. Palaeontographica, 39, 56 pp.

Schellwien, E. 1900. Die Fauna der Trogkofelschichten in den Karnischen Alpen und den Karawanken, 1: Die Brachiopoden. Abhandlungen der KaiserlichKöniglichen Geologischen Reichsanstalt, Wien, 16, 122 pp., 15 láms.

Schulz, W. 1858. Descripción geológica de la provincia de Oviedo. Impr. José González, Madrid, 138 pp.

Sokolskaja, A.N. 1950. Chonetidae Russkoy Platformy.
Trudy Paleontologicheskogo Instituta, Akademiya Nauk SSSR, 27, 107 pp., 13 pls. (en ruso).

Stevens, C.H. 1962. Stratigraphic significance of Pennsylvanian brachiopods in the McCoy area, Colorado. Journal of Paleontology, 36, 617-629, pl. 9196.

Sturgeon, M.T. and Hoare, R.D. 1968. Pennsylvanian brachiopods of Ohio. Bulletin Geological Survey Ohio, 63, 1-95, 22 láms.

Truyols, J. 1983. La Cuenca Carbonífera Central. In: Carbonífero y Pérmico de España (Coord. C. Martínez Díaz). X Congreso Internacional de Estratigrafía y Geología del Carbonífero, Madrid, 1983, 60-81.

Verneuil, E. De 1845. Paléontologie. Mollusques, brachiopodes. In: Murchinson, R. I., Verneuil, E. de and Keyserling, A. de. Géologie de la Russie d'Europe. J. Murray ed. (London) \& Bertrand ed. (París), 2, 3, 37 294, pl. 11, 15-18.

Verneuil, E. de 1846. Note sur les fossiles du terrain carbonifère de Pola de Lena et de Mieres del Camino. Bulletin de la Société Géologique de France, 3, 454-457.

Villa, E. 1995. Fusulináceos carboníferos del E de Asturias (N de España). Biostratigraphie du Paléozoique, 13, 261 pp., 36 lám.

Wagner, R. H. and Álvarez-Vazquez, C. 1991. Floral characterisation and biozones of the Westphalian D stage in NW Spain. Neues Jahrbuch Geologie Paläontologie Monatshefte, 183, 171-202.

Wagner, R. H., Winkler Prins, C.F. and Riding, R.E. 1971. Lithostratigraphic units of the lower part of the Carboniferous in northern León, Spain (with a "Note on some goniatite faunas" by C.H.T. Wagner-Gentis). Trabajos de Geología, Universidad de Oviedo, 4, 603663.

Waterhouse J. B. 1975. New Permian and Triassic brachiopod taxa. University of Queesland, Department of Geology, 7(1) 1-23, 2 pl.

Waterhouse J. B. 1981. Early Permian brachiopods from Ko Yao Noi and near Kravi, Southern Thailand. In: The Permian stratigraphy and palaentology of Southern Thailand (Eds. J.B. Waterhouse, K. Pitakpaivan \& N. Mantapit). Geological Survey Memoir, 4, 1-213, 34 pl.

White, C.A. 1862. Description of new species of fossils from the Devonian and Carboniferous rocks of the Mississippi Valley. Boston Society of Natural History, Proceedings, 9, 8-33.

White, C.A. and St. John, O. 1867. Descriptions of new Subcarboniferous Coal-Measure fossils, collected upon the Geological Survey of Iowa; together with a notice of new generic characters involved in two species of brachiopoda. Chicago Academy Sciences, 1, 115-127.

Winkler Prins, C.F. 1968. Carboniferous Productidina and Chonetidina of the Cantabrian Mountains (NW Spain): systematics, stratigraphy and palaeoecology. Leidse Geologische Mededelingen, 43, 41-126, 8 tab., 9 pls. 